\title{
High-Resolution Downscaled Simulations of Warm-Season Extreme Precipitation Events in the Colorado Front Range under Past and Future Climates*
}

\author{
Kelly Mahoney, Michael Alexander, James D. Scott, And Joseph Barsugli \\ NOAA/ESRL, and CIRES, University of Colorado Boulder, Boulder, Colorado
}

(Manuscript received 19 October 2012, in final form 9 May 2013)

\begin{abstract}
A high-resolution case-based approach for dynamically downscaling climate model data is presented. Extreme precipitation events are selected from regional climate model (RCM) simulations of past and future time periods. Each event is further downscaled using the Weather Research and Forecasting (WRF) Model to storm scale (1.3-km grid spacing). The high-resolution downscaled simulations are used to investigate changes in extreme precipitation projections from a past to a future climate period, as well as how projected precipitation intensity and distribution differ between the RCM scale $(50-\mathrm{km}$ grid spacing) and the local scale (1.3-km grid spacing). Three independent RCM projections are utilized as initial and boundary conditions to the downscaled simulations, and the results reveal considerable spread in projected changes not only among the RCMs but also in the downscaled high-resolution simulations. However, even when the RCM projections show an overall (i.e., spatially averaged) decrease in the intensity of extreme events, localized maxima in the high-resolution simulations of extreme events can remain as strong or even increase. An ingredients-based analysis of prestorm instability, moisture, and forcing for ascent illustrates that while instability and moisture tend to increase in the future simulations at both regional and local scales, local forcing, synoptic dynamics, and terrain-relative winds are quite variable. Nuanced differences in larger-scale and mesoscale dynamics are a key determinant in each event's resultant precipitation. Very high-resolution dynamical downscaling enables a more detailed representation of extreme precipitation events and their relationship to their surrounding environments with fewer parameterization-based uncertainties and provides a framework for diagnosing climate model errors.
\end{abstract}

\section{Motivation}

\section{a. Understanding extreme weather in a climate framework}

Precipitation extremes impact human social and economic systems through flooding, erosion, and property damage; thus, understanding the link between climate and precipitation extremes attracts considerable attention (e.g., Karl et al. 2008). While evidence from both models and observations suggests that precipitation extremes increase as global temperatures rise, detailed information about such changes (e.g., when, where, by how much) is lacking (e.g., Frei et al. 2006; Fowler et al.

\footnotetext{
* Supplemental information related to this paper is available at the Journals Online website: http://dx.doi.org/10.1175/JCLI-D-1200744.s1.

Corresponding author address: Kelly Mahoney, CIRES, University of Colorado Boulder, 325 Broadway, R/PSD1, Boulder, CO 80309. E-mail: kelly.mahoney@noaa.gov
}

2007; Pall et al. 2007; Lenderink and van Meijgaard 2008, 2010; O'Gorman and Schneider 2009).

Climate models are used to assess potential changes in future extreme events. While climate model performance has improved considerably in recent years, the simulation of extremes in particular is known to be fraught with substantial deficiencies. Recent studies indicate that horizontal resolution is a key factor in a model's ability to simulate observed extreme precipitation characteristics and that statistical methods to downscale coarser datasets often result in systematic spatial distribution and intensity errors, particularly with respect to the highest moments of variability [i.e., the most extreme events; e.g., Haylock et al. (2006); Wehner et al. (2010); Gutmann et al. (2012)]. Because of the small scales of convective motions, the realistic simulation of warm-season precipitation extremes remains a salient challenge in climate model development and improvement. The convective motions that drive much warm-season midlatitude precipitation are not resolved in the current generation of global climate models (GCMs) or in most regional climate models (RCMs). The 
combination of coarse model resolution and the resulting requisite parameterization of processes such as convection and boundary layer mixing are known to have deficiencies including (but not limited to) (i) difficulty simulating the diurnal cycle and representing interactions with parameterized radiative effects (e.g., Baldwin et al. 2002; Guichard et al. 2004; Mahoney and Lackmann 2006), (ii) large sensitivity to soil conditions (e.g., Hohenegger et al. 2009), (iii) unusual vertical heating profiles (e.g., Baldwin et al. 2002; Chao 2012), and (iv) unrealistic convective system organization and motion (e.g., Bukovsky et al. 2006; Li et al. 2008; Moncrieff and Liu 2006; Mahoney and Lackmann 2007; Pritchard et al. 2011; Newman and Johnson 2012).

Given these challenges, how can methods to understand the effects of climate change on extreme precipitation events be improved? In this study, we investigate the utility of a multistep downscaling approach by which global-scale data $(\sim 100-200-\mathrm{km}$ grid spacing) are dynamically downscaled to the regional scale $(\sim 50-\mathrm{km}$ grid spacing), and the regional-scale data are then further downscaled to the storm scale ( $\sim 1-\mathrm{km}$ grid spacing). In so doing, we address the following questions:

1) Does the intensity of heavy precipitation events change in future climate scenarios?

2) If precipitation intensity changes are found, why? That is, how do projected changes in instability, moisture, and forcing for ascent affect projected precipitation and convective system properties?

3) What are the strengths and limitations of a highresolution event-based downscaling approach?

\section{b. Previous research}

Early studies considering the effects of climate change on small-scale extreme weather (e.g., floods, tornadoes, and hail) largely relied upon the linkage of proxy atmospheric indicators and observations. Brooks et al. (2003) used global reanalysis data to illustrate that the product of convective available potential energy (CAPE) and vertical wind shear could be used as a reasonable representation of the observed distribution of severe thunderstorm observations. Trapp et al. (2007a) used RCM data to illustrate that a proxy for severe thunderstorm formation increased under elevated greenhouse gas forcing. Similar approaches to understand the role of climate change on small-scale extreme events have been used in other studies as well (e.g., Del Genio et al. 2005; Diffenbaugh et al. 2005; Marsh et al. 2007, 2009; Trapp et al. 2007b; Van Klooster and Roebber 2009; Trapp et al. 2009), but such studies are often limited by (i) an inadequate record of historical storm and precipitation data, (ii) the coarse resolution of the data analyzed (usually global reanalyses and climate model simulations), and (iii) the often tenuous connection between large-scale environmental parameters and smallscale weather extremes.

Many statistical and dynamical methods exist to downscale climate data, each approach offering unique strengths and weaknesses (e.g., Fowler et al. 2007; Gutmann et al. 2012). Even within the two major classifications of downscaling, there are numerous downscaling options for a given objective or region. Dynamical downscaling using RCMs has gained considerable popularity, offering improved resolution of topography, land surface heterogeneity, and atmospheric motions. Many studies have found RCMs to better reproduce regional precipitation patterns relative to GCMs (e.g., Dickinson et al. 1989; Giorgi and Bates 1989; Diffenbaugh et al. 2005; Liang et al. 2006; Leung and Qian 2009; Gutowski et al. 2010); however, identifying and understanding the sources of RCM error and bias remain a challenge (e.g., Bukovsky 2012; Salzmann and Mearns 2012). One method toward better understanding such errors is to examine RCM performance on a limited set of key cases of interest, as prototyped by foundational RCM papers such as Giorgi and Bates (1989) and Dickinson et al. (1989).

While high-resolution climate simulations are often limited by computational constraints, previous studies have begun to pursue such an approach. Trapp et al. (2007b) used a model simulation with explicit (nonparameterized) convection to illustrate that global reanalysis data can be dynamically downscaled to produce extreme convective precipitation in approximately the correct place and time. Trapp et al. (2010) used explicit convection and $4.25-\mathrm{km}$ grid spacing to simulate warmseason regional climate statistics for severe weather over a 10-yr period, demonstrating that, despite biases, the high-resolution simulations adequately captured the diurnal cycle and geographic distribution of convective weather [i.e., type 2 downscaling; Castro et al. (2005)]. Rasmussen et al. (2011) present high-resolution simulations of annual snowfall in Colorado that show excellent agreement with observations if horizontal grid spacings at or below $6 \mathrm{~km}$ are used. Ohara et al. (2011) explored methods of maximizing precipitation in high-resolution simulations of a single extreme event toward better understanding potential effects of climate change. While computational constraints usually limit high-resolution methods to a short temporal period of integration or few climate realizations tested, the increase in model resolution presumably affords more plausible simulations of intense localized precipitation (e.g., Kendon et al. 2012; Lackmann 2013).

Decision-making groups such as water resources managers are also pursuing downscaling as a means to 
assess climate change impacts on a local scale (e.g., Hostetler et al. 2011). Projected increases in extreme precipitation events prompt reassessment of flooding impacts and design criteria for water infrastructure, particularly in the western United States (e.g., Milly et al. 2008; Barsugli et al. 2009; Hossain et al. 2010; Ohara et al. 2011; Dominguez et al. 2012). Addressing these challenges requires current and projected future climate information at high spatial and temporal resolution, and such data are generally not provided by current climate models.

\section{c. The Colorado Front Range: A flood-prone test region}

We choose to study the impact of climate change on precipitation extremes in the Colorado Front Range. The Colorado Front Range is typically defined as the region extending northward from central Colorado (around Colorado Springs, Colorado) to the Wyoming border and from the eastern foothills of the southern Rocky Mountains out to the eastern plains of Colorado (Fig. 1). This region is chosen for its susceptibility to flash flooding, the general regional concern for water (e.g., supply, shortages, dam safety, and reservoir storage practices), and also the presence of a sharp terrain gradient upon which convective storms trigger. (This latter aspect helps to constrain regionally the selection of extreme precipitation events with similar dynamical forcing, in contrast to regions such as the Great Plains where convective triggering is more regionally diffuse.) Flash floods are a concern in this region because of the combination of steep complex terrain and the potential for sustained heavy rainfall when moist easterly flow impinges on the mountains and rises to form precipitation in an environment of relatively weak midlevel flow (e.g., Toth and Johnson 1985; Trier et al. 2010).

Precipitation projections from both the global and regional climate multimodel ensembles indicate a general drying trend in mean warm-season precipitation across Colorado, but the details of projected changes differ, particularly for extreme events across all seasons (e.g., Wang et al. 2009; Dominguez et al. 2012; Salzmann and Mearns 2012; Wehner 2013; Alexander et al. 2013). Discrepancies in these projections likely stem from competing effects of increasing temperatures, shifting storm tracks, and the multitude of ways that changes in thermodynamic variables and storm dynamics may interact with the region's complex terrain. Because GCMs cannot represent the complexity of the topography along the Colorado Front Range and high spatial resolution is needed to represent the dynamics of extreme precipitation, downscaling appears to offer potential toward better understanding climate change effects on

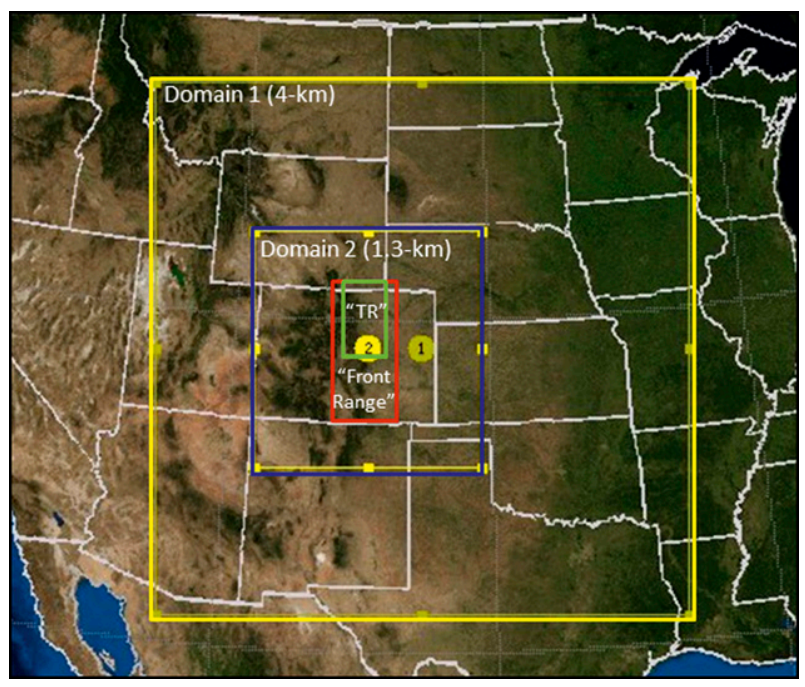

FIG. 1. Map of west-central United States showing the case selection target region used for analysis (TR; green box), the Colorado Front Range region (Front Range; red box), the outer 4-km WRF Model domain (Domain 1; yellow box), and the inner 1.3-km WRF Model domain (Domain 2; blue box).

heavy precipitation in this region. Several recent studies have focused on evaluating downscaling methods and climate change projections for this region precisely for the reasons stated above (e.g., Wang et al. 2009; Rasmussen et al. 2011; Dominguez et al. 2012; Gutmann et al. 2012; Salzmann and Mearns 2012). By exploring high-resolution downscaling of extreme precipitation events, we investigate whether such an approach can improve confidence in projected changes through either increasing model agreement or providing physical process-based insight into why given changes occur. Alternatively, we consider whether the additional simulations and increased spatial detail only widen the spectrum of possible future projections.

\section{Methods}

GCM simulations are first downscaled to $50-\mathrm{km}$ grid spacing as part of the North American Regional Climate Change Assessment Program (NARCCAP; Mearns et al. 2011). Extreme precipitation events are selected from the NARCCAP RCM projections. Each event is then further downscaled using the Weather Research and Forecasting (WRF) Model to generate a storm-scale (1.3-km grid spacing) simulation in which convective parameterization is omitted. Thus, the RCM data provide an intermediate step from coarse-resolution global climate simulations to the very high-resolution simulations of single extreme events. As RCMs resolve the general topographic gradient of the Colorado Front Range and 
resulting regional-scale circulations, the RCM intermediate step also allows for a more relevant comparison of RCM fields to the high-resolution simulations that direct use of a GCM would not. A unique aspect of this study is the use of a tiered dynamical downscaling framework that better resolves key physical processes to illustrate why, physically, changes in extreme precipitation are projected to occur.

\section{a. Regional climate model data}

Initial and boundary conditions for the high-resolution event-based simulations are produced from three independent RCMs from NARCCAP. NARCCAP provides a multimodel ensemble of RCMs driven by a set of atmosphere-ocean GCMs over a domain covering the conterminous United States and most of Canada. Each GCM-RCM combination simulates a past (1971-2000) and future (2041-70) period, and the regional downscaling is performed to $50-\mathrm{km}$ grid spacing. The driving GCMs utilize the A2 scenario from the Special Report on Emissions Scenarios of the Intergovernmental Panel on Climate Change (IPCC), in which carbon dioxide $\left(\mathrm{CO}_{2}\right)$ levels increase to roughly 600 ppm by 2070 (Nakicenovic and Swart 2000).

The NARCCAP RCM experiments discussed in this manuscript are

1) GT: the time-slice experiment from the Geophysical Fluid Dynamics Laboratory (GFDL) Climate Model, version 2.1 (CM2.1). This experiment downscales the fully coupled ocean-atmosphere GFDL CM2.1 global model for the past and future NARCCAP time periods (i.e., time slices; e.g., Cubasch et al. 1995) using sea surface temperatures and sea ice distributions from the coupled GCM as boundary conditions for a higherresolution $(50 \mathrm{~km})$ global simulation using the GFDL Atmospheric Model, version 2.1 (AM2.1; see http:// www.narccap.ucar.edu/about/timeslices.html);

2) CW: a regional climate version of the WRF Model driven by the global National Center for Atmospheric Research (NCAR) Community Climate System Model, version 3 (CCSM3); and

3) CR: the Regional Climate Model, version 3, driven by the Canadian Centre for Climate Modelling and Analysis (Pal et al. 2007) Coupled General Circulation Model, version 3 (CGCM3).

The largest precipitation events are identified and grouped according to the RCM and use the following naming conventions. When referring to the NARCCAP RCMs, the datasets will be called GT-rcm, CW-rcm, and CR-rcm, respectively (although the GT experiment was not technically simulated with an RCM but rather the higher-resolution atmospheric GCM). When referring to the high-resolution downscaled simulations, those simulations will be designated GT-wrf, CW-wrf, and CR-wrf.

\section{b. Extreme event case selection}

Extreme precipitation cases for both past and future projections of each NARCCAP RCM were identified using warm-season (June, July, and August) 24-h precipitation totals within a target region (TR) centered over the Front Range of the Colorado Rocky Mountains (Fig. 1). Here, we take extreme to indicate the largest daily precipitation events in the available RCM datasets but acknowledge that semantics to describe such events may differ in engineering and stakeholder communities (e.g., Bonnin et al. 2011). Precipitation totals from June, July, and August were ranked according to the largest 24-h precipitation (1500-1500 UTC) total at any one RCM grid point in the target region [note that increasing the area over which precipitation was averaged to rank events (to a moving region with dimensions $200 \mathrm{~km} \times$ $200 \mathrm{~km}$ within the target region) did not significantly alter the resulting rank order]. The 10 largest 24 -h precipitation values from unique events for 1971-2000 and 2041-70 defined the 10 largest cases for the past and future simulations, respectively; our case selection criteria thus, in essence, selects extreme environments from each RCM for use in the high-resolution downscaling approach described below. This approach has some advantages over other possible downscaling methods such as simulation of a limited time-slice and "pseudo-global warming" thermodynamically perturbed simulations (e.g., Schär et al. 1996; Hara et al. 2008; Kawase et al. 2009; Rasmussen et al. 2011; Lackmann 2013) because it allows for the finer resolution of efficiently extracted extreme events, and it accounts for (RCM projected) changes in dynamical weather patterns and shifts in storm tracks.

\section{c. High-resolution model simulations}

The Advanced Research WRF (ARW; Skamarock et al. 2007) Model is used to generate the high-resolution (1.3-km grid spacing) simulations of each RCM's top 10 extreme precipitation events. WRF Model version 3.1.1 was utilized for all of the high-resolution simulations in this study. The WRF Model is a fully compressible nonhydrostatic model and uses a terrain-following hydrostatic pressure vertical coordinate.

Initial conditions are constructed directly from RCM output as obtained from the NARCCAP dataset, with no additional adjustment of $\mathrm{CO}_{2}$ or other greenhouse gases. The WRF Model outer domain (4-km grid spacing) includes much of the central and western United 
States, and the inner nest (1.3-km grid spacing) is centered on Colorado (Fig. 1). One-way nesting is used and each simulation is executed according to the model configuration details listed in Table 1. Each WRF simulation was initialized approximately $6 \mathrm{~h}$ prior to the largest 3-h precipitation total as depicted by the RCM simulation of the event, and each WRF simulation lasts $24 \mathrm{~h}$ in duration. Model output for each case is produced hourly, and the internal model time step is $8 \mathrm{~s}$. Experiments were conducted to evaluate the sensitivity of simulation results to both model physical parameterizations (particularly to cloud microphysics and planetary boundary layer parameterization) and to model initialization time within a 9-h range around the largest 3-h precipitation amount. Overall results were not qualitatively affected by these changes (i.e., variation in precipitation amounts were on the order of $1-10 \mathrm{~mm}$ ); although it remains an open question as to how to best initialize high-resolution simulations from coarseresolution initial data in a way that allows for optimal spinup of intermediate-scale features. The WRF Model setup used for these downscaling experiments was also evaluated by simulating observed events initialized with both the National Centers for Environmental Prediction (NCEP) North American Regional Reanalysis (NARR) and the NCEP-NCAR reanalysis data to confirm that this high-resolution WRF Model framework is indeed skillful for the warm-season convective event types in which we are interested (e.g., Mahoney et al. 2012).

\section{d. Comparison of RCM precipitation with reanalysis data}

The three RCM datasets (GT-rcm, CW-rcm, and CR-rcm) were chosen based on data availability and an attempt to represent as large a portion of NARCCAP's RCM-generated spectrum of extreme precipitation changes as logistically possible. At the commencement of this project, only two model experiments (GT-rcm and $\mathrm{CW}$-rcm) had available the required three-dimensional data and were thus used out of necessity. The third model (CR-rcm) was chosen later, out of a slightly larger pool of then available model experiments. CR-rcm was selected in part to represent a wetter RCM projection, when compared to the more moderate GT-rcm and relatively dry $\mathrm{CW}-\mathrm{rcm}$ precipitation projections (Fig. 2; Tables 2 and 3). Recent work suggests that weighting or culling NARCCAP models based on skill in representing key climatological features of a given region may offer increased confidence in overall results (e.g., Bukovsky and Mearns 2012), though this option was not available for this study. Therefore, while three model experiments selected from an already limited
TABLE 1. WRF Model set-up and parameterization for downscaled simulations.

\begin{tabular}{ll}
\hline \multicolumn{1}{c}{ Model version } & WRF (ARW) version 3.1.1 \\
\hline Duration & $24 \mathrm{~h}$; output frequency is $1 \mathrm{~h}$ \\
Grid & 1.3-km grid spacing (within a 4-km outer \\
& nest) \\
& $574 \times 601$ gridpoint domain (outer \\
& domain $450 \times 450)$ \\
& 28 vertical levels \\
& Explicit convection (no convective \\
physics & parameterization) \\
& WSM6 microphysics \\
& YSU planetary boundary layer (PBL) \\
& scheme \\
& Noah land surface model; Monin- \\
& Obukhov surface layer physics \\
& Dudhia; Rapid Radiative Transfer Model \\
& (RRTM) radiation physics \\
Initial and boundary & NARCCAP (Mearns et al. 2009); CT, CW, \\
conditions & and CR simulations. Boundary \\
& conditions updated every $6 \mathrm{~h}$. \\
\hline
\end{tabular}

NARCCAP experiment cannot capture the entire parameter space of possible regional climate change signals, enhancing initial condition model diversity provides a step toward sampling a fuller distribution of future climate possibilities.

While most NARCCAP models indicate a drying trend in future summer mean precipitation for this region, the highest precipitation percentiles (i.e., greater than the 99th percentile of daily rainfall as examined here) can show a differing result (Alexander et al. 2013). The three RCMs chosen for this study are compared to the NARR (Mesinger et al. 2006) data (32-km grid spacing) in order to compare RCM-produced extreme events to the heaviest regional rainfall events as represented by NARR. The top 10 selected events from each RCM historical period are compared with the top 10 historical events (from the NARR data period 1979present). The 10 event spatial average precipitation from the top 10 events in the twentieth-century NARCCAP simulations relative to the analogous NARR quantity show that the GT-rcm and CR-rcm simulations tend to have larger average precipitation values relative to the NARR analysis, and CW-rcm tends to have smaller average values relative to NARR (Fig. 2; Tables 2 and 3). The spatial structure and distribution of the RCM average precipitation also differ significantly from NARR, with most of the model simulations showing a generally more (grid) boxy structure with the maxima centered on various parts of the target region. Such differences are somewhat expected due in part to the coarser model resolution relative to NARR. While a comparison to reanalysis data ideally provides some insight into model 

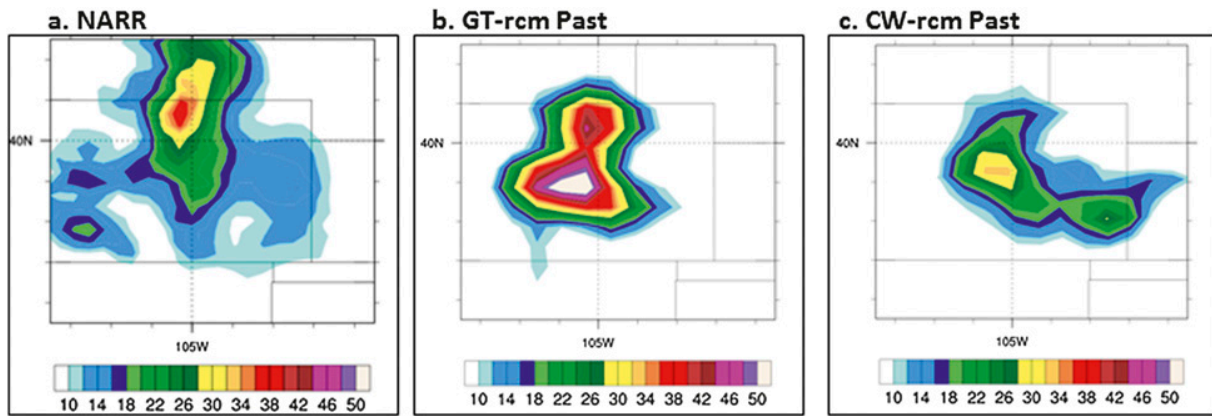

d. CR-rcm Past
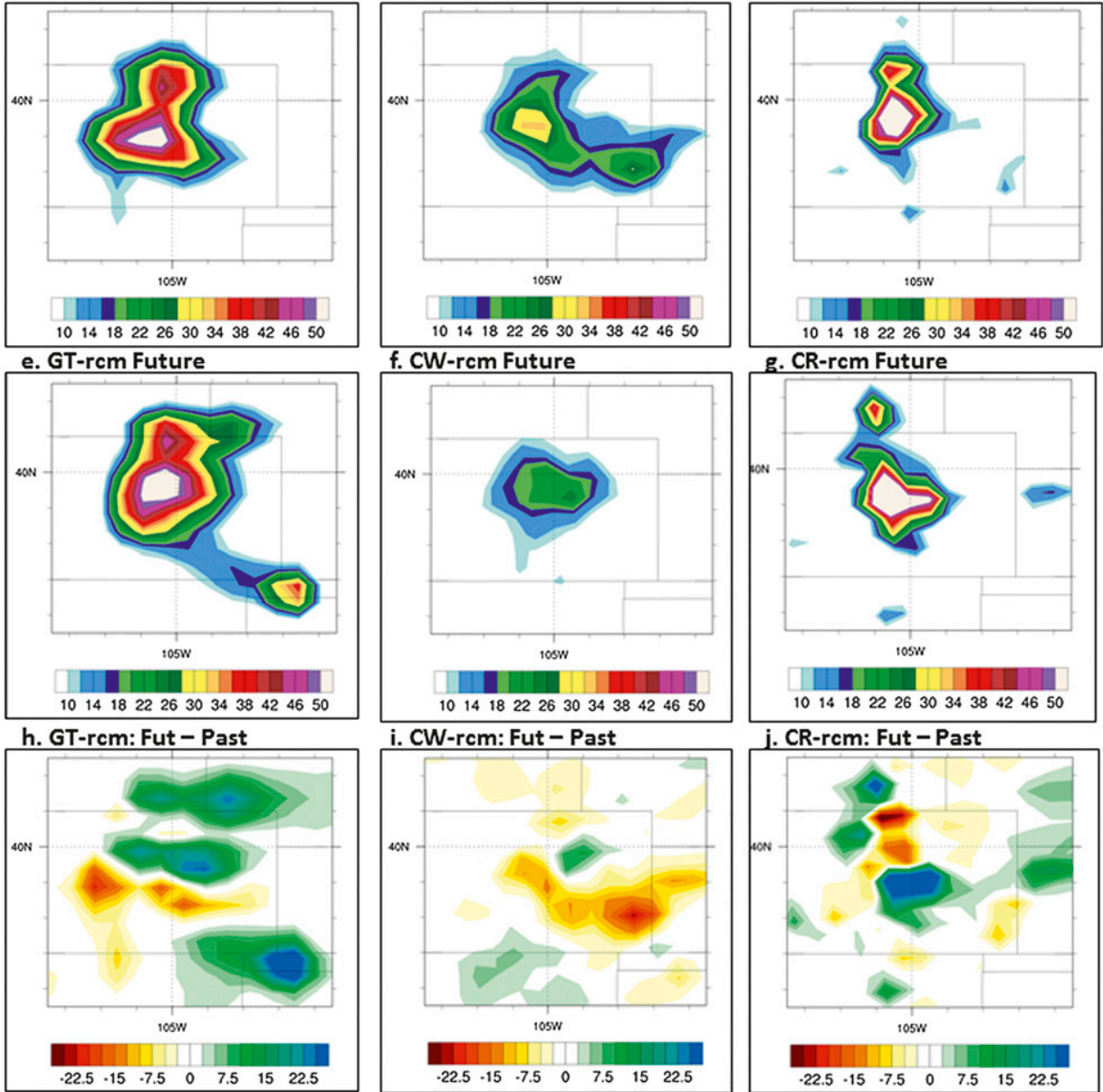

FIG. 2. (a) Average 24-h accumulated precipitation for the top 10 NARR events for the target region (mm). (b)-(g) As in (a), but for each NARCCAP RCM past and future period, as labeled. (h)-(j) Difference fields for future - past top 10 event averages.

performance in the historical period [and Alexander et al. (2013) show that NARR precipitation is closely matched to the NARCCAP mean precipitation for both lighter and heavier precipitation events], one must also consider that NARR is higher resolution (32-km grid spacing) and assimilates different data sources. Furthermore, Fig. 2a averages only 10 observed (historical) events, which are completely independent of the events projected by the RCMs. The spatial structure of a given RCM's past and future precipitation are more similar to one another than to that of other models or that of NARR, indicating that each model's preferred regional precipitation pattern is reasonably sampled by 10 events. NARR may also have difficulty representing large precipitation amounts in mountainous terrain and has other known limitations and errors that have been documented as well (e.g., Mesinger et al. 2006; Bukovsky and Karoly 2007; West et al. 2007; Dominguez et al. 2012; Hughes et al. 2012). Thus, the comparison is offered here as a basic benchmark against a proxy for observations, but deviations between NARR and the RCM top 10 events not only reflect model bias in pattern and magnitude but also the independence of the events considered.

TABLE 2. Comparison of WRF, NARCCAP, and NARR 24-h precipitation values $(\mathrm{mm})$ averaged over all top 10 events for the max 24-h precipitation value at a single grid point. Positive changes/future increases (negative changes/future decreases) shown with plus (minus) sign.

\begin{tabular}{lccc}
\hline & \multicolumn{3}{c}{ Avg max 24-h } \\
precipitation (mm) & \\
\cline { 2 - 3 } & Past & Future & Change (\%) \\
\hline NARR & 62.7 & - & - \\
GT-rcm & 144 & 189 & +31.3 \\
CW-rcm & 86.7 & 60.4 & -30.3 \\
CR-rcm & 204.7 & 271.2 & +32.5 \\
GT-wrf & 125 & 207 & +65.6 \\
CW-wrf & 101 & 103 & +2.0 \\
CR-wrf & 100.7 & 80.1 & -20.5 \\
\hline
\end{tabular}


TABLE 3. As in Table 2, but for the domain-average precipitation (over the 1.3-km inner WRF Model domain).

\begin{tabular}{lccc}
\hline \hline & \multicolumn{2}{c}{$\begin{array}{c}\text { Avg domain-average } \\
\text { 24-h precipitation } \\
\end{array}$} & \multicolumn{2}{c}{$(\mathrm{mm})$} & \\
\cline { 2 - 3 } & Past & Future & Change (\%) \\
\hline NARR & 10.4 & - & - \\
GT-rcm & 8.3 & 11.2 & +34.9 \\
CW-rcm & 7.0 & 5.5 & -21.4 \\
CR-rcm & 5.4 & 6.3 & +16.7 \\
GT-wrf & 5.1 & 9.3 & +82.4 \\
CW-wrf & 6.1 & 4.0 & -34.4 \\
CR-wrf & 3.9 & 2.1 & -46.2 \\
\hline
\end{tabular}

NARCCAP RCM simulations were also produced using reanalysis-driven boundary conditions. While such simulations can be useful for assessing model performance compared to observations and to assess the efficacy of the NARCCAP downscaling simulation sequence, they are not used explicitly here because reanalysis-driven downscaled simulations (i) were not produced for all three of the models that we utilize, (ii) do not reflect any possible GCM-provided bias that would be introduced to the corresponding future simulation, and (iii) are themselves not well matched with observations of warm-season extreme precipitation, due in part to the challenges described above (e.g., Wehner 2013). Therefore, references herein to historical or past events do not connote observed historical events (Mearns et al. 2009). Additional NARCCAP RCM detail appears in Mearns et al. (2009) and references therein (see also http://narccap.ucar.edu/ data/rcm-characteristics.html).

\section{High-resolution downscaling results}

To illustrate the increase in spatial detail gained from downscaling the RCM $50-\mathrm{km}$ grid spacing data to $1.3-\mathrm{km}$ grid spacing, Fig. 3 compares the largest past and future GT-rcm (i.e., GFDL time slice from NARCAPP) precipitation event with the respective downscaled GT-wrf (i.e., GFDL time slice downscaled by WRF) counterpart. Resolving both finer-scale terrain detail as well as convective motions (both updrafts and downdrafts) explicitly allows the high-resolution simulations to resolve precipitation in spatial detail that more closely mimics observed precipitation patterns relative to the coarse bull's-eye types of features produced at the RCM scale. The increase in resolution also affords improved representation of the formation, organization, and movement of organized convective systems (e.g., Bukovsky et al. 2006; Pritchard et al. 2011), as suggested by the propagation of the convective system from the point of convective initiation over elevated terrain eastward to the eastern plains of Colorado.

Because displaying individual images for each of the 60 simulated cases is impractical for publication, we instead average fields of interest from the 10 downscaled simulations for each past/future set of simulations driven by the three RCMs. When high-resolution data for 10 separate events are averaged together, it is difficult to gain a sense of the intensity of individual events (e.g., compare the intensity of the single events from the GT-wrf simulation in Fig. 3 to the averages shown in Figs. 4a,d); thus, plots of total precipitation for each individual high-resolution simulation are provided in the supplemental material (Figs. S1-S3).

It is clear from the individual event perspective that the CR-wrf (i.e., CGCM3 + RCM3 downscaled by WRF) simulations (Fig. S3 in the supplemental material) often do not produce precipitation amounts that would be expected for extreme events. The discrepancy between the large amount of precipitation produced by the RCM for these events and the lack of precipitation produced by the high-resolution downscaling exposes a fundamental disconnect between precipitation generation in the RCM versus in the high-resolution downscaled simulations. Further analysis of the CR-rcm (i.e., CGCM3 + RCM3 per NARCCAP) experiment reveals that in many of the top 10 cases, this particular RCM (the Regional Climate Model, version 3; Pal et al. 2007) induces persistent and unphysical upslope flow, mostly likely in response to terrain-induced poorly ventilated differential heating, resulting in large "gridpoint storms" (e.g., Zhang et al. 1988; Giorgi 1991; Molinari and Dudek 1992; West et al. 2007; Chao 2012). An example of this is illustrated in Fig. S4 of the supplemental material; while a full description is beyond the scope of this manuscript, it is important to note that the CR-wrf simulations are strongly biased by the RCM used to initialize them. Specifically, an RCM-generated gridpoint storm (though note that the resulting precipitation often spans multiple grid points) will be counted as one of the top 10 events to be downscaled, but the downscaled simulation will not produce similar amounts of precipitation since it is not susceptible to the parameterization-induced weaknesses found in the RCM. The simulations are still, however, included in the ensuing analysis with the purposes of (i) intercomparing the extreme event environmental characteristics of all three RCMs, (ii) disclosing a potential error source that likely affects extreme precipitation generation in other GCMs and RCMs (e.g., Chao 2012), and (iii) divulging a potential limitation of this specific downscaling method that should be considered by similar regional-to-high-resolution downscaling efforts. 

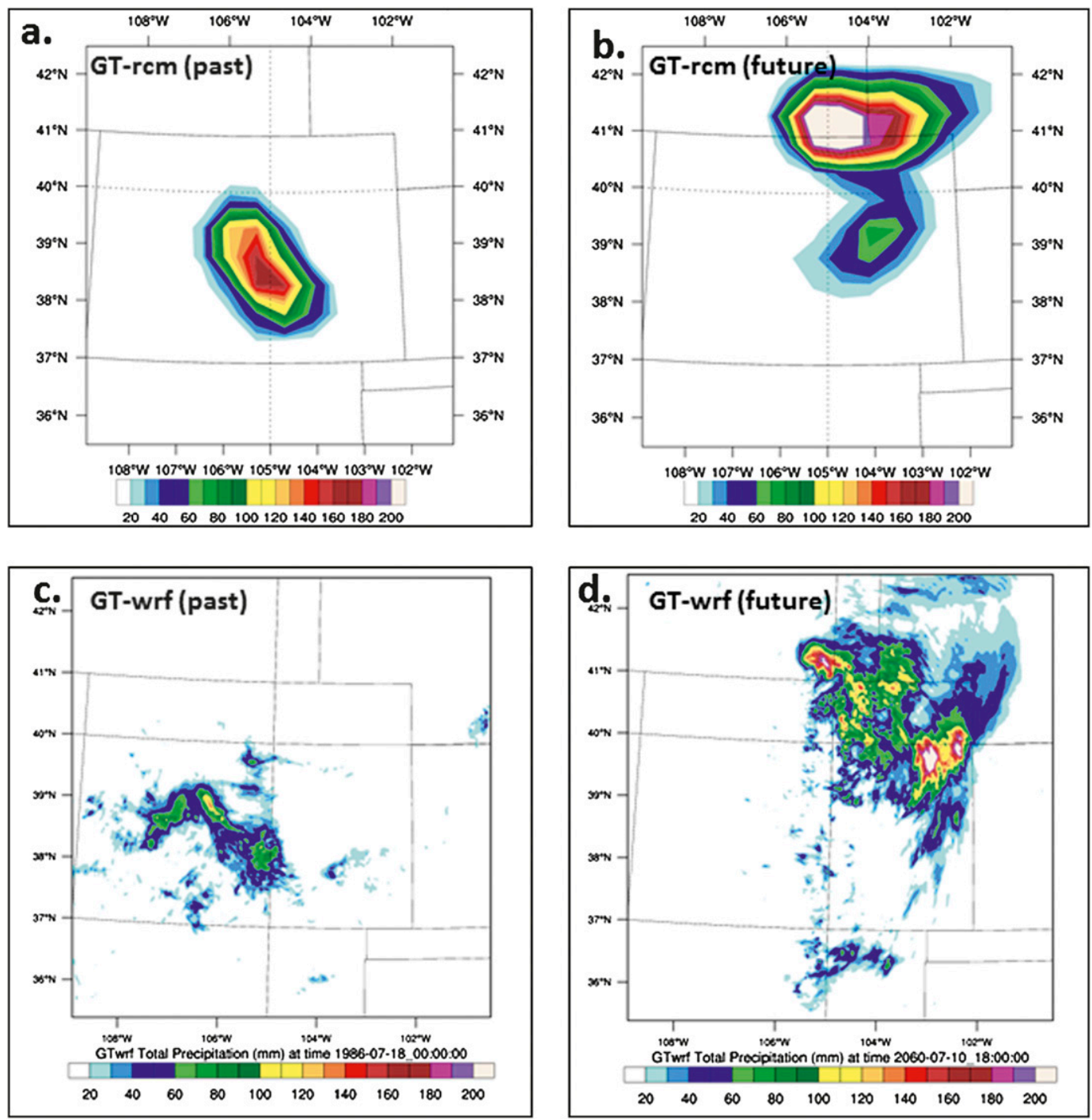

FIG. 3. The 24-h accumulated precipitation ( $\mathrm{mm}$ ) for the top event from (a) GT-rcm (past), (b) GT-rcm (future), (c) GT-wrf (past), and (d) GT-wrf (future).

\section{a. Intermodel precipitation comparison}

There are significant differences between the three sets of high-resolution simulations, particularly between the GT-wrf simulations that produce considerably more precipitation on average than those by $\mathrm{CW}$-wrf or CRwrf in both the past and future simulations (Fig. 4). Relative to the average 24-h NARR precipitation for the top 10 events for this region (Fig. 2a), both the CWwrf and the CR-wrf appear to simulate events with generally weaker intensity than would be suggested by the historical climatology. Though the precipitation maximum produced by GT-wrf is better matched to that of the NARR data in terms of absolute value (Fig. 2a), the simulated maximum is smaller and located to the southwest of the Front Range target region. Quantitatively, the NARR domain-averaged precipitation exceeds that of the high-resolution WRF simulations, but the modeled precipitation has larger local maximum precipitation values (Table 2). The maximum precipitation at the WRF $(1.3 \mathrm{~km})$ scale is expected to be larger than that for either the NARR $(32 \mathrm{~km})$ or NARCCAP $(50 \mathrm{~km})$ scales, making the decrease in maximum precipitation between the GT and CR RCMs and the high-resolution WRF simulations even more striking. This would indicate that, for the cases shown here, the RCMs are likely overestimating precipitation at their grid scale. The NARR reference point is provided in Table 2 as a basic benchmark, again caveated by the fact that (i) the difference in grid spacing between 

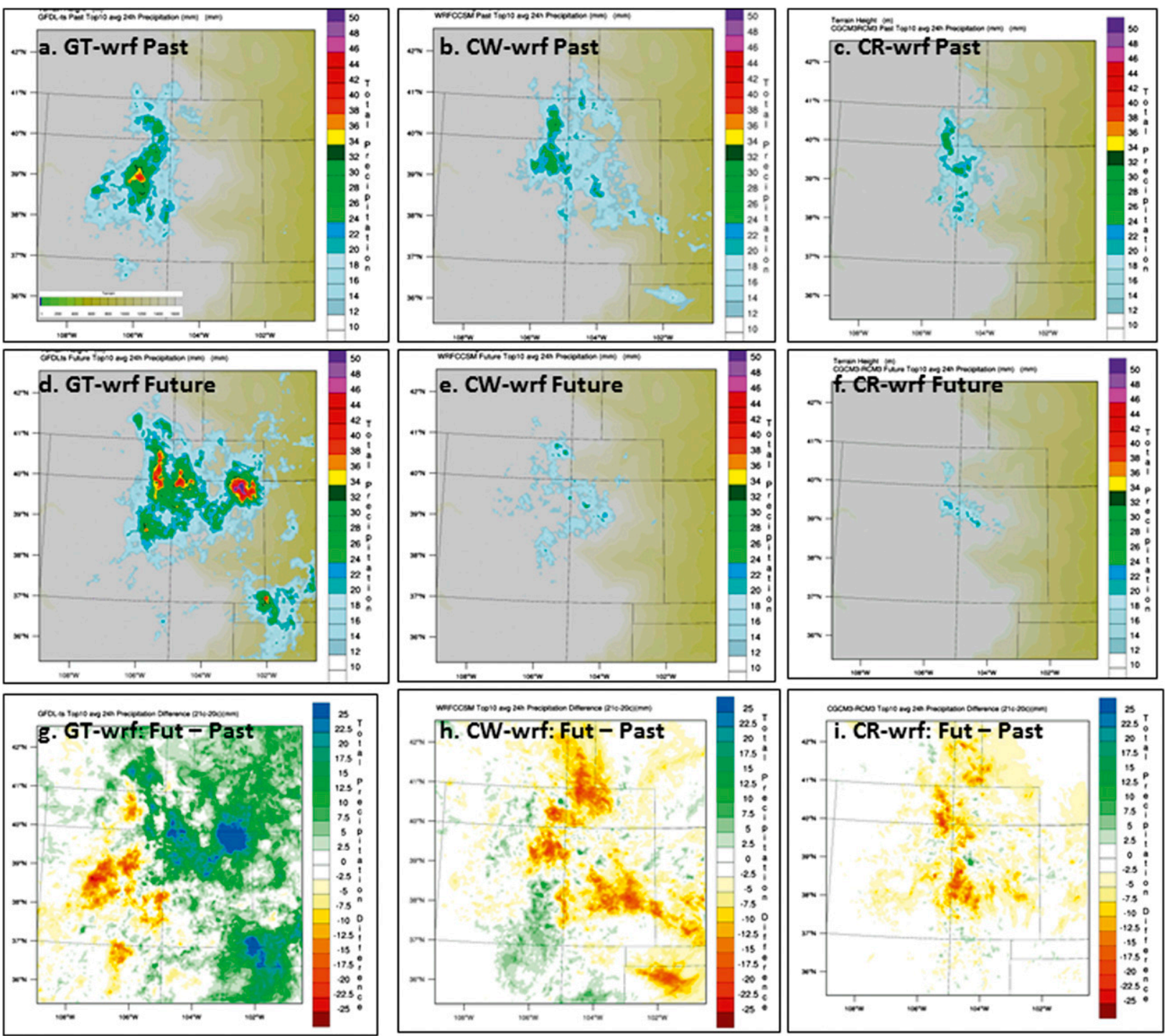

FIG. 4. The 24-h accumulated precipitation average for (a) GT-wrf, (b) CW-wrf, and (c) CR-wrf top 10 past simulations. (d)-(f) As in (a)-(c), but for top 10 future simulations. (g)-(i) Difference fields for future - past top 10 event averages.

NARR $(32 \mathrm{~km})$ and the WRF downscaled experiments $(1.3 \mathrm{~km})$ likely contributes to the discrepancy in maximum precipitation values and spatial distribution and that (ii) the collection of 10 events (while representing the most intense precipitation events contained by the dataset) remains a relatively small sample size to be considered climatology.

The average of the 10 GT-wrf past simulations yields a 45-mm rainfall maximum over the higher terrain of central Colorado (Fig. 4a). In contrast, the future GT-wrf simulations produce three main precipitation maxima that each exceed $45 \mathrm{~mm}$ and span an eastwardextended spatial region from the eastern edge of the Rocky Mountains to the eastern plains of Colorado (Fig. 4d). The average precipitation difference from the past to the future across the two sets of 10 runs from GT-wrf is clearly an increase from the target region, eastward (Fig. 4g). The presence of three precipitation maxima in the future average field suggests differences in convective system organization and motion and illustrates that the future event environments considered here support larger rainfall amounts over the eastern part of Colorado relative to the past top event environments.

The CW-wrf events are generally smaller both in spatial extent and 24-h maximum precipitation values (Fig. S2); therefore, the event averages are considerably smaller relative to the GT-wrf simulations (cf. Figs. 4a,b). Similar to the GT-wrf simulations, the past highresolution runs tend to maximize precipitation over the eastern edge of the Rocky Mountains, but in contrast to 
GT-wrf, precipitation totals decrease on average in the future simulations (Figs. 4b,e). The pattern of the $\mathrm{CW}$-wrf precipitation difference field is almost reversed from that seen in the GT-wrf precipitation difference field (Figs. 4g,h), with future increases (decreases) in event average precipitation in the eastern part of the domain for GT-wrf (CW-wrf). As the CR-wrf experiment produces few events with notable precipitation, average precipitation values are low in both the past and future simulations (Figs. 4c,f,i). Because of the aforementioned challenges demonstrated by CR-rcm, changes indicated in its downscaled precipitation fields are of limited practical significance.

Domain-averaged and gridpoint maximum precipitation values are given in Tables 2 and 3. Not only do the future changes differ between the three sets of downscaled simulations, the values also differ considerably from the RCM-indicated values. If CR-wrf is discounted because of its lack of intense precipitation in most cases, then an increase in localized maxima is noted in most of the GT-wrf and CW-wrf simulations. While the increase in the CW-wrf event average local maximum is negligible, it is important to note that relatively strong localized maxima still occur in individual simulations despite a decrease in the overall precipitation associated with the $\mathrm{CW}$ top future events. This result may be particularly relevant for applications sensitive to changes in maximum local precipitation amounts. Note also that if we consider a hypothetical set of 30-yr WRF simulations using 1.3-km grid spacing, it may contain events in its top 10 that are not in the top 10 events identified using RCM data (as discussed in section 2b). Therefore, the results in Tables 2 and 3 represent lower bounds with respect to WRF extreme event precipitation totals.

\section{b. Ingredients-based analysis}

We now examine the three main ingredients for warm-season convective storms in this region: moisture, lift, and instability. The concept of ingredients-based analysis for flash floods was developed and popularized by Doswell et al. (1996), in which flash flood-producing storms are broken down into a framework that somewhat separately considers the processes driving deep moist convection: sufficient moisture, environmental instability, and a mechanism capable of lifting a parcel of air to its level of free convection (LFC). We adopt this framework in order to better understand how largescale environmental changes may be contributing to changes in extreme precipitation projections and also to explain differences between model results.

The following analysis documents the changes in ingredients at the initialization time of the high-resolution
WRF simulations. Changes in the larger-scale environment at WRF's initial time are inherited directly from the driving RCMs; therefore, the ingredients-based discussion below is valid for both the RCM environments and the WRF simulations, at least at the initial times.

\section{1) Moisture}

Precipitable water (PW) measures the total moisture in the atmospheric water column. The average of the 10 initial event environments of all three model experiments show an overall moistening from the past to the future in the Front Range target region (Figs. 5h,i,j), though the magnitude of the change itself and the absolute moisture content varies considerably (Figs. 5b-g). PW in the GT-wrf simulations increases from the past to the future simulations in an area concentrated largely over the eastern plains partially in response to stronger southerly flow and enhanced moisture transport from the Gulf of Mexico, but the pattern weakens over higher terrain and even shows some drying tendencies in the southwestern part of the domain (Fig. 5h). The CW-wrf and CR-wrf events show a more uniform average moistening of the atmospheric column (Figs. 5i,j), consistent with general expectations of enhanced atmospheric moistening due to global climate warming. In terms of the absolute amount of moisture, GT-wrf has the largest PW values overall, followed by CR-wrf, and $\mathrm{CW}$-wrf is the driest; CR-wrf appears to compare most closely to reanalysis-derived values for PW values associated with extreme events in this region, even though precipitation was poorly represented in this experiment and downscaled simulations showed a decrease from the past to future periods (Fig. 5a).

While PW provides insight into the total moisture content, variations in moisture with height are critical to storm structure, strength, and precipitation efficiency, and there are considerable differences with respect to moisture changes with height between the three driving RCMs (Fig. 6). Within the Front Range target region, the GT-wrf initial environments show slight (likely negligible) drying at very low levels (i.e., the surface to $750 \mathrm{hPa}$ ) and moistening aloft, with a maximum dewpoint $\left(T_{d}\right)$ increase of $4^{\circ} \mathrm{C}$ around $500 \mathrm{hPa}$ (Fig. 6a). $\mathrm{CW}$-wrf shows relatively constant low-level moistening $\left(T_{d}\right.$ increase of $\left.2^{\circ} \mathrm{C}\right)$ from the surface to $600 \mathrm{hPa}$, then sharp midlevel drying between 500 and $300 \mathrm{hPa}$ (Fig. 6b). Different from both GT-wrf and CW-wrf, the CR-wrf initial environments show a nearly uniform level of moistening ( $T_{d}$ increase of approximately $\left.2^{\circ} \mathrm{C}\right)$ from the surface to the tropopause (Fig. 6c).

While low-level drying (and upper-level warming, discussed below) in the GT-wrf average environment 

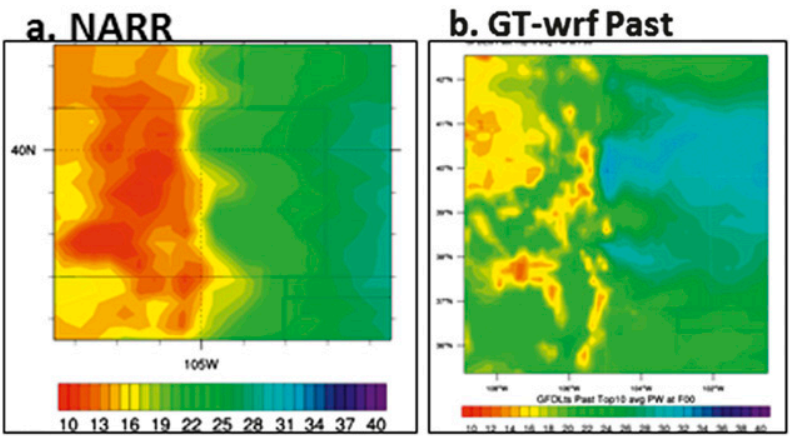

e. GT-wrf Future
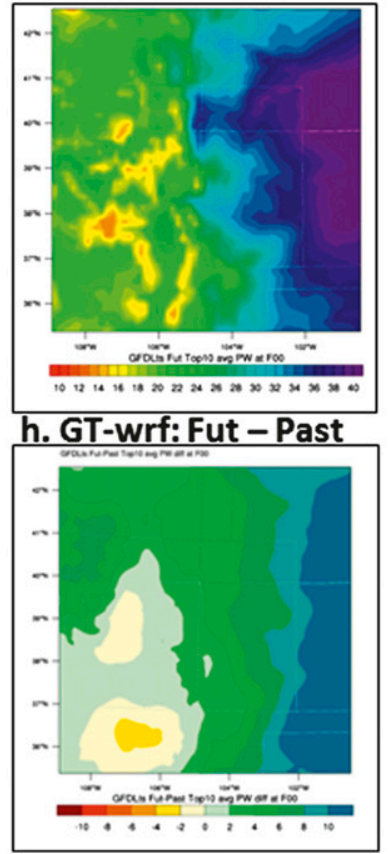

c. CW-wrf Past

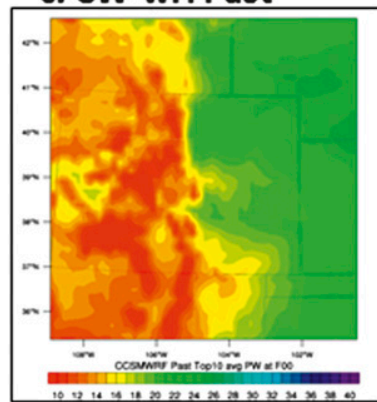

f. CW-wrf Future
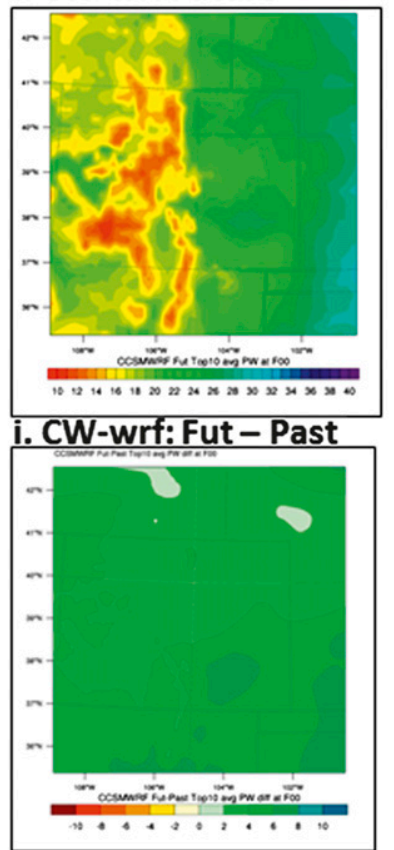

d. CR-wrf Past

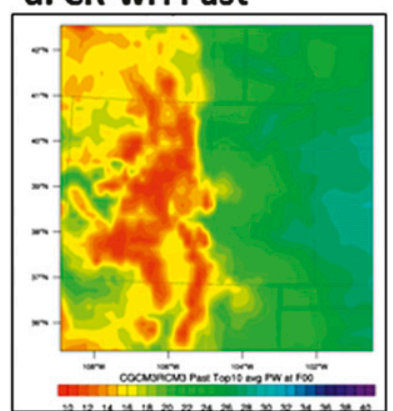

g. CR-wrf Future

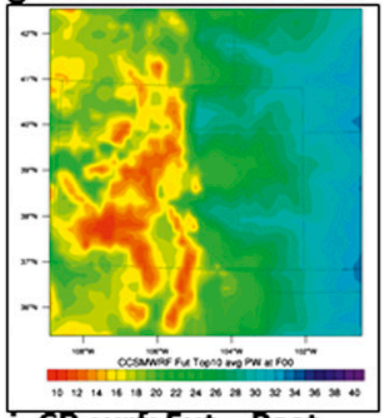

FIG. 5. (a) Average PW (mm) for top 10 NARR events at 2100 UTC. (b)-(d) As in (a), but for initialization times of all past simulations for (b) GT-wrf, (c) CW-wrf, and (d) CR-wrf. (e)-(g) As in (b)-(d), but for future simulations. Difference (future - past) of top 10 event averages for (h) GT-wrf, (i) CW-wrf, and (j) CR-wrf.

may at first slightly hinder the initiation of convection, large increases in midlevel moisture likely reduce dry air entrainment, system weakening, and strong evaporative downdrafts that can ultimately cut off the moisture supply to a storm and render it short lived. Ample midlevel moisture may thus be a key feature in allowing the GT-wrf events to maintain greater strength over a larger area and longer duration than in the $\mathrm{CW}$-wrf or CR-wrf simulations. Conversely, the midlevel dry air in the $\mathrm{CW}$-wrf average initial environment may contribute to the small size and more isolated nature of the $\mathrm{CW}$-wrf simulated events. Note that midlevel mixing of dry air is a process that is generally not well represented by convective parameterization (CP) schemes but is more fully resolved at storm scale (e.g., Del Genio and Wu 2010).

\section{2) InSTABILITY}

Thermal variations with height are also critical to the production of ample buoyancy such that low-level air can be lifted to the lifting condensation level (LCL) and LFC. One measure of such instability is CAPE (e.g., Bluestein 1993); this quantity addresses surface-based instability, and it is generally well suited for the present analysis.

In a warmer and moister future climate, it is intuitive that preconvective CAPE might increase (e.g., Williams and Renno 1993; Ye et al. 1998; Van Klooster and Roebber 2009). However, given that the magnitude of warming and moistening may be greater at mid- or upper levels relative to lower levels, it is possible that environmental stability can increase via lapse-rate stabilization 
GT-wrf

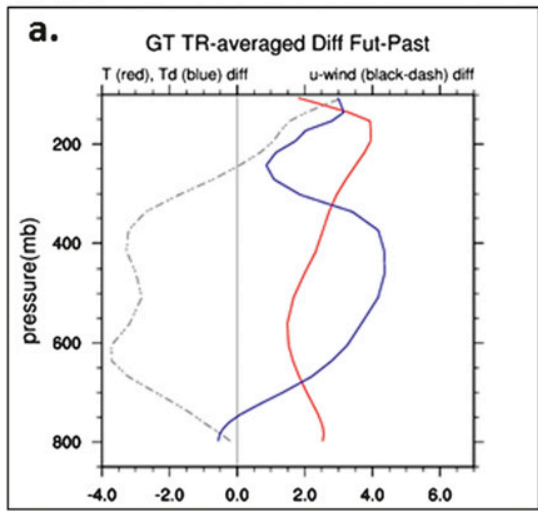

CW-wrf

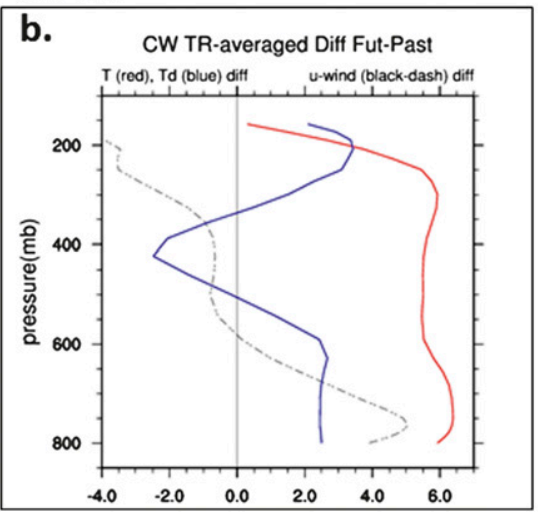

CR-wrf

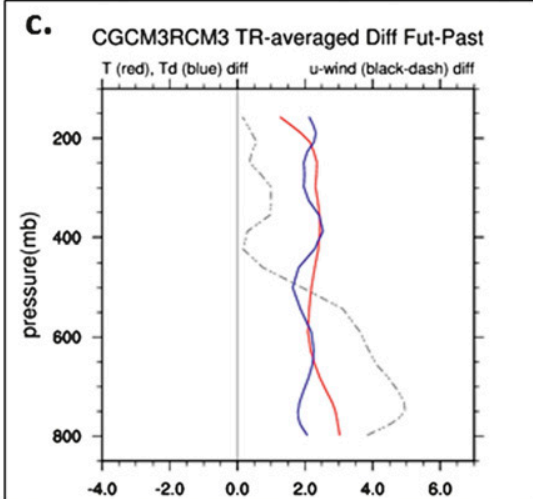

FIG. 6. Vertical profile difference plot (future - past top 10 simulations) at model initial time of temperature (red line; ${ }^{\circ} \mathrm{C}$ ), dewpoint (blue line; ${ }^{\circ} \mathrm{C}$ ), and the east-west wind component (black dashed line; $\mathrm{kt}, 1 \mathrm{kt} \approx 0.5 \mathrm{~m} \mathrm{~s}^{-1}$ ) for an area average over the Front Range TR for (a) GT-wrf, (b) CW-wrf, and (c) CR-wrf. The $y$ axis is pressure (hPa).

and thereby reduce the intensity of convection (e.g., Marsh et al. 2009; Hill and Lackmann 2011). As the events analyzed here were selected based on intense warmseason rainfall (and thus presumably possessed significant CAPE), it is not surprising that all of the average environments show at least some areas of CAPE $>500 \mathrm{~J} \mathrm{~kg}^{-1}$ (Fig. 7). However, both the changes and absolute magnitudes show considerable spread: CW-wrf and CR-wrf averages both show increases of CAPE from 200 to $800 \mathrm{~J} \mathrm{~kg}^{-1}$ in the target region, but decreases in CAPE are found in CR-wrf west of the continental divide, and large decreases are found in GT-wrf throughout the central part of the domain, particularly over higher terrain (Figs. 7h,i,j). Consistent with larger PW values, GT-wrf events also have much higher overall CAPE values than either CW-wrf or CR-wrf, and CR-wrf appears to compare most closely to NARR-analyzed CAPE values in similar historical events (Fig. 7a).

Since CAPE integrates the effect of both temperature and moisture variations with height, vertical soundings and profiles are useful to diagnose what specifically produces a given CAPE value. The low-level increases in both temperature and moisture across the Front Range target region in CW-wrf and CR-wrf environments result in CAPE increases (Figs. 6b,c). Note that despite increases in CAPE, precipitation generally decreases for the events in these two experiments, underscoring the importance in resolving convection explicitly rather than using a proxy such as CAPE to extrapolate likely changes in precipitation. That is, a warmer and moister environment does not guarantee stronger storms when all factors are considered, and if an ingredientbased approach is sought to understand changes to extreme precipitation in coarse-resolution datasets, consideration of alternative ingredients may be needed.
Conversely, CAPE decreases from the past to the future across this particular area in the GT initial environments, but more importantly to the ensuing convection, CAPE remains the largest of the three experiments in terms of absolute value and thus intense storms still develop.

\section{3) FORCING FOR ASCENT}

Even with ample moisture and sufficient instability, some type of forcing for ascent is generally required for precipitation to form. In the Colorado Front Range, this forcing often comes in the form of simple upslope flow (i.e., easterly winds impinge on the high terrain and moist air is forced to rise). Differences in the low-level easterly flow between the past and future top $10 \mathrm{GT}$ cases show an increase in future easterly (blue) upslope flow in the Front Range target region and across eastern Colorado, consistent with increased moisture advection and larger future PW values as described above (Figs. 6, 8, and 9). Conversely, both CW-wrf and CR-wrf show weakened easterly flow across the target region for these cases; this is likely a key determining factor in the smaller amounts of precipitation in $\mathrm{CW}$-wrf and CR-wrf over central and eastern Colorado. In terms of easterly wind strength compared to the reanalysis-based observed event composite (Fig. 8a), the three RCMs display general agreement with respect to the magnitude and distribution of low-level flow, indicating that the upslope forcing for ascent expected from observations is indeed captured in each prestorm initial environment. CR has a stronger easterly component over eastern Colorado relative to GT and CW, which is consistent with the development of unphysical gridpoint storms as previously described.

Future changes in the vertical profile of the east-west component of the horizontal wind across the target region corroborate these results; Fig. 6 shows the average 
a. NARR

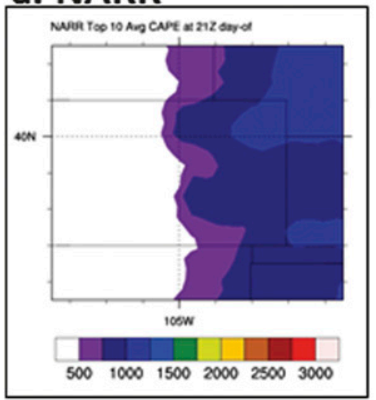

b. GT-wrf Past

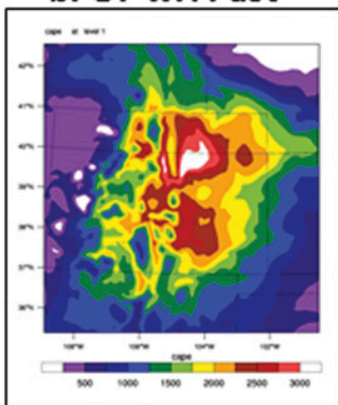

e. GT-wrf Future

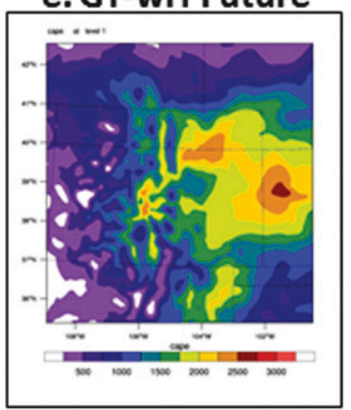

h. GT-wrf: Fut - Past

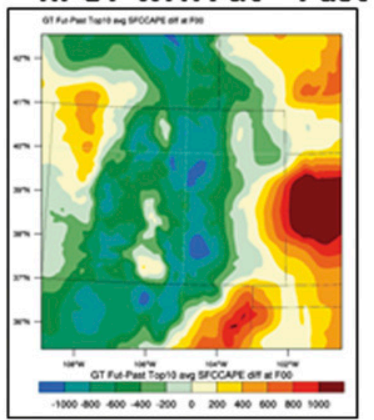

c. CW-wrf Past

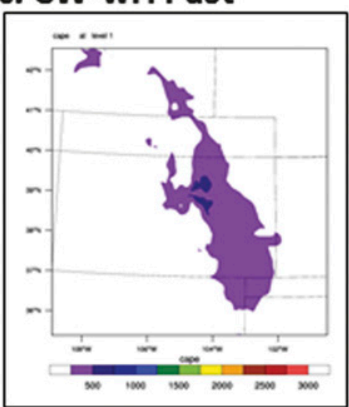

f. CW-wrf Future

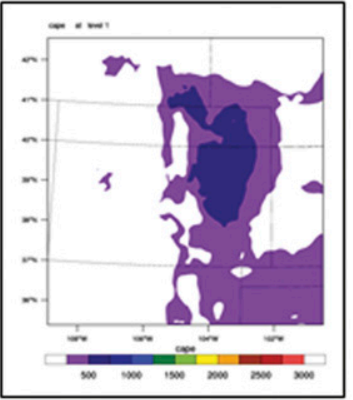

i. CW-wrf: Fut - Past

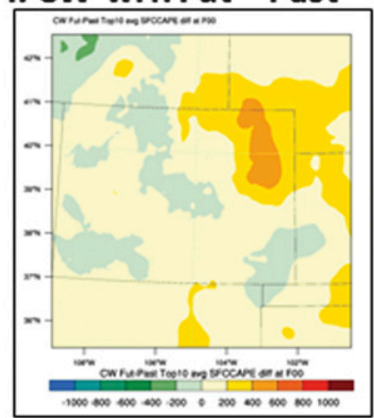

d. CR-wrf Past

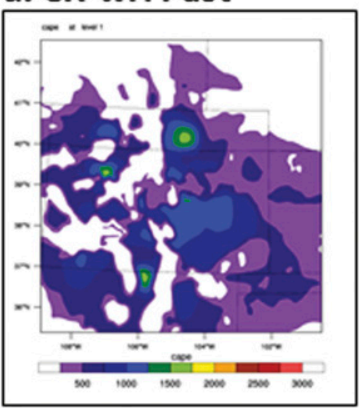

g. CR-wrf Future
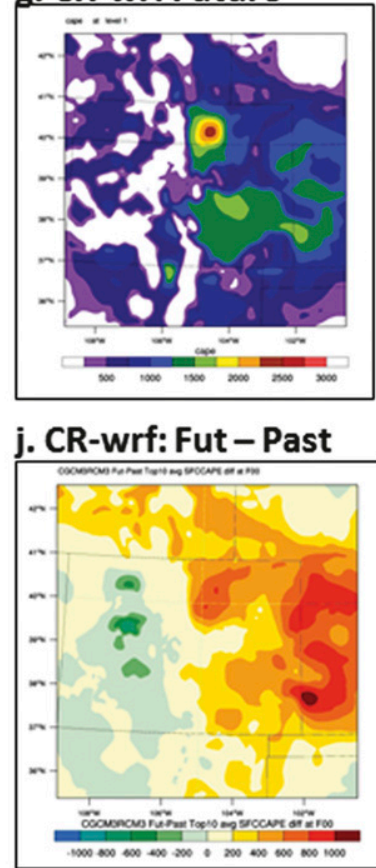

FIG. 7. (a) Average surface-based CAPE ( $\mathrm{J} \mathrm{kg}^{-1}$ ) for top 10 NARR events at 2100 UTC. (b)-(d) As in (a), but for initialization times of all past simulations for (b) GT-wrf, (c) CW-wrf, and (d) CR-wrf. (e)-(g) As in (b)-(d), but for future simulations. Difference (future past) of top 10 event averages for (h) GT-wrf, (i) CW-wrf, and (j) CR-wrf.

increasing easterly flow from 800 to $300 \mathrm{hPa}$ in the GT initial environments from the past to the future runs. Past to future decreases in easterly winds (and in some cases, a transition to westerly downsloping flow) are found in both $\mathrm{CW}$ and $\mathrm{CR}$ from the surface to midlevels.

While warm-season convection can be triggered merely by upslope flow in the presence of ample moisture and low-level instability, larger-scale forcing for ascent is also of interest. Synoptic-scale forcing can strengthen/accelerate more local lifting mechanisms (e.g., Doswell 1987), and it is of additional interest here because RCMs using $50-\mathrm{km}$ grid spacing should be well suited to resolve motions on synoptic scales. Surface winds and 700-hPa upward vertical motion $(w>0)$ show that both easterly low-level flow and larger-scale lift ( $w$; associated with synoptic-scale high pressure located north of the Colorado Front Range, not shown) is most prominent in the GT simulations, both past and present, as well as in the CW past average environment (Fig. 9). The synoptic surface circulation patterns as indicated by the 10-m wind become diluted in the $\mathrm{CW}$ future average environment, and also reveal marked differences between the CR initial environments and the other experiments (Fig. 9).

\section{Summary and discussion}

\section{a. Summary}

This study explores the utility of a high-resolution event-based model downscaling approach designed to better understand how and why extreme precipitation 

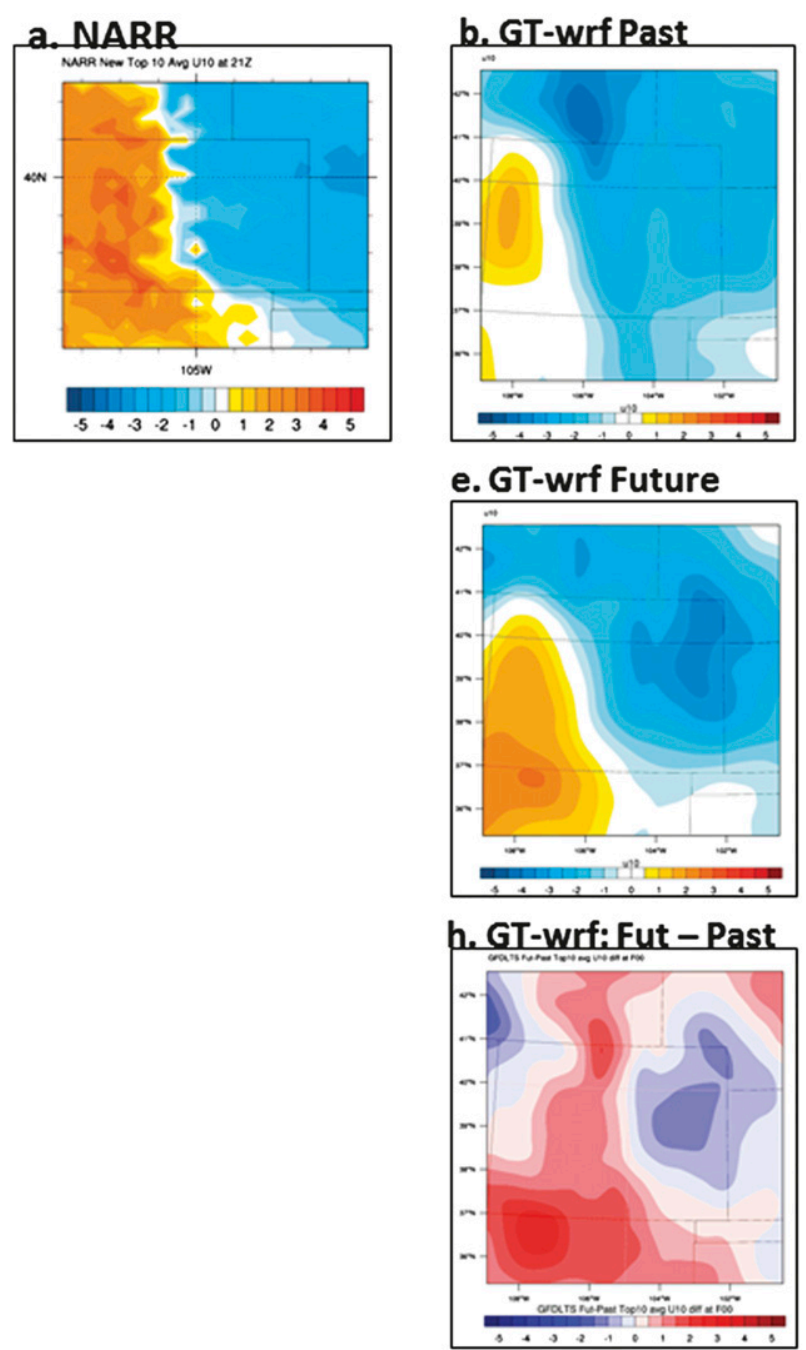
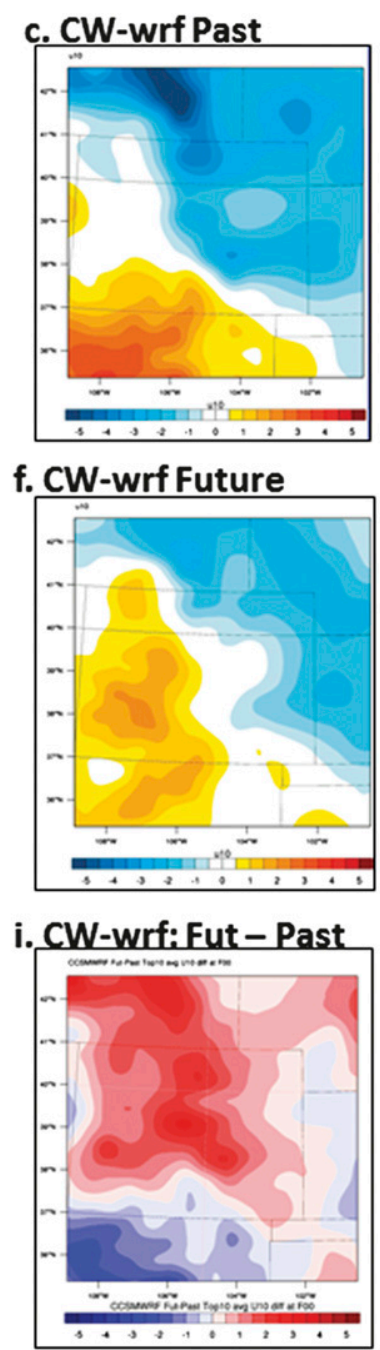
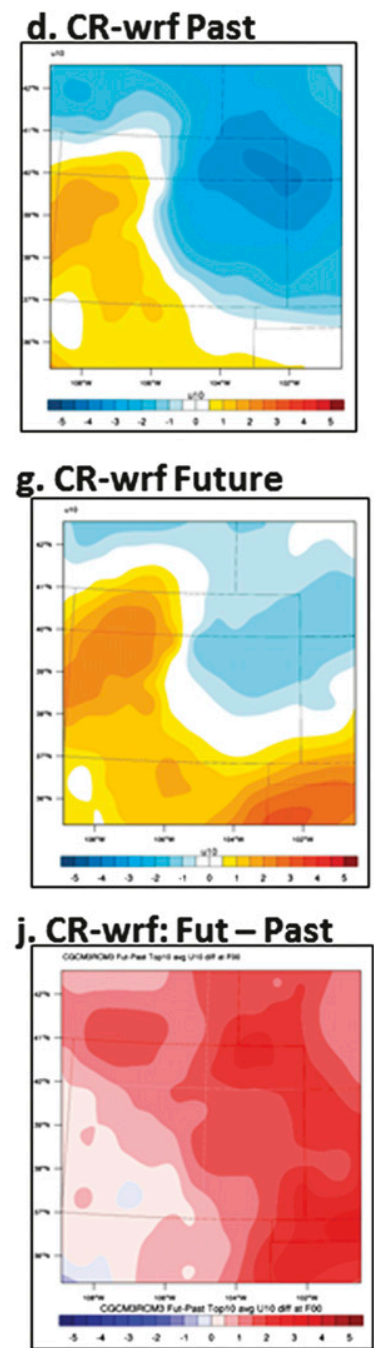

FIG. 8. (a) Average $u$ wind (east-west direction; $\mathrm{m} \mathrm{s}^{-1}$ ) for top 10 NARR events at 2100 UTC; (b)-(d) as in (a), but for initialization times of all past simulations for (b) GT-wrf, (c) CW-wrf, and (d) CR-wrf. (e)-(g) As in (b)-(d), but for future simulations. Difference (future - past) of top 10 event averages for (h) GT-wrf, (i) CW-wrf, and (j) CR-wrf.

events may change in future climates, as well as identify the strengths and limitations of the specific model downscaling method. The region of interest for this study is the Colorado Front Range, but the general method may be applicable to other regions.

Three RCM projections for the periods 1970-2000 and 2040-70 are used to identify and initialize the top 10 largest precipitation events for further high-resolution (1.3-km grid spacing) downscaling. Substantial differences exist between the three RCMs themselves in terms of precipitation projections over the Colorado Front Range, as well as between the RCMs and the downscaled simulations with respect to the absolute amounts of precipitation (both in the localized maxima and domain-averaged quantities). The high-resolution downscaled simulations suggest an increase in the intensity of extreme precipitation according to one model (GT-wrf), little change in another (CW-wrf), and a decrease in the intensity of extreme events in the third (CR-wrf). However, the collection of high-resolution downscaled simulations suggest that even given a regional climate model projection that shows an overall (i.e., spatially averaged) decreasing intensity for extreme events, localized maxima within individual extreme events can remain as intense or increase.

Though this specific collection of high-resolution simulations may not provide a definitive answer as to whether extreme precipitation will change in this region, the storm-scale information and ingredients-based analysis affords insight into how changes in large-scale climate parameters may in turn affect small-scale storms. The three RCM projections used here all indicate an 

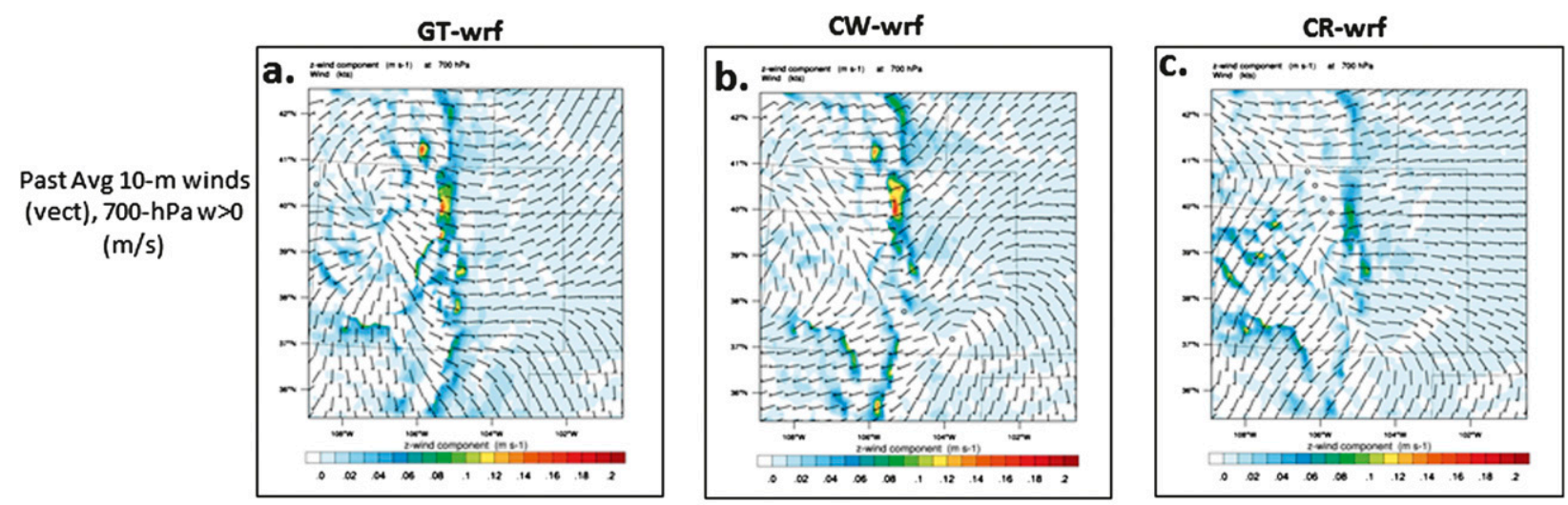

Future Avg 10-m winds (vect), 700 $\mathrm{hPa} w>0(\mathrm{~m} / \mathrm{s})$
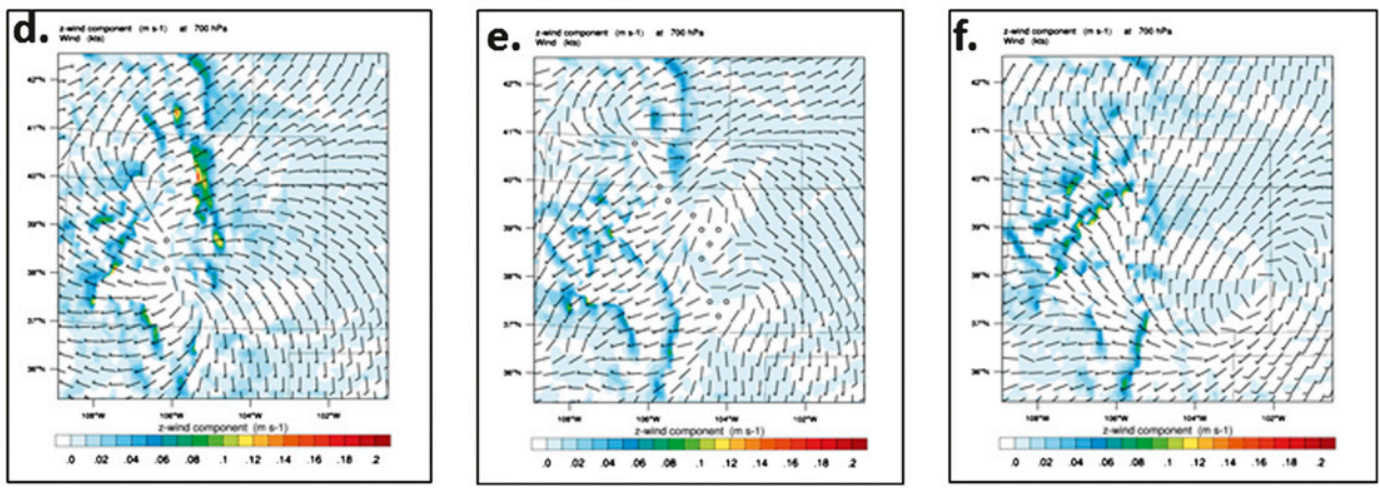

FIG. 9. The 10-m winds (barbs; kt) and 700-hPa vertical velocity ( $\mathrm{m} \mathrm{s}^{-1}$; shaded as in the color bar) for (a) GT-wrf, (b) CW-wrf, and (c) CRwrf (past); and (d)-(f) as in (a)-(c), but for top 10 future event averages.

increase in total moisture (precipitable water), two of the three (CW and $\mathrm{CR}$ ) indicate an increase in CAPE, and only one (GT) indicates an increase in upslope flow for the extreme event environments examined. That the environmental changes are often inconsistent with the projected changes in rainfall demonstrates a key advantage of this method over proxy-based approaches that use larger-scale datasets to infer a connection between a single environmental parameter and precipitation. This potential drawback of proxy-based approaches (and an advantage of the present method) is exemplified by the increased future initial environment $\mathrm{PW}$ and CAPE in $\mathrm{CW}$-wrf and CR-wrf but (counter to what a proxy-based framework would suggest) decreased future precipitation in both experiments.

The storm-scale [horizontal grid spacing $O(1 \mathrm{~km})$ ] simulations presented here resolve multiscale interactions of potentially competing effects that are generally not well represented by model parameterization schemes (e.g., dry air entrainment diluting otherwise strong updrafts as indicated in the $\mathrm{CW}$-wrf experiments), as well as allow the analysis of parameters that are generally not provided in coarser-scale data such as cloud-scale parameters and hydrometeor concentrations (e.g., Mahoney et al. 2012). We contend that the physically consistent high-resolution downscaling framework for intense precipitation events offers potentially useful detail but also expands the range of possible climate change impacts. While such an expansion is often deemed valuable in research applications [e.g., adding "good spread" to an ensemble of model forecasts; Eckel and Mass (2005)], for decision makers an expansion of climate change possibilities to consider may present an additional challenge in deciding how to most appropriately use high-resolution information.

Discrepancies between the high-resolution simulations with explicit convection and the RCMs that utilize cumulus parameterization prompt additional investigation into the generation of extreme precipitation by larger-scale regional and global climate models. Despite beginning with approximately the same environment, the RCM events and the WRF-downscaled events show considerable disagreement in both intensity and spatial distribution of precipitation (cf. Figs. 2 and 4). In particular, the vast discrepancy between the RCM- and WRF-generated precipitation in the CR experiment exposes a key limitation of using GCMs and coarse-resolution RCMs to evaluate warm-season convectively driven extreme precipitation events: coarseresolution models require parameterizations that are 
often inherently incapable of realistically representing extreme events. In the CR-wrf example, the lack of heavy precipitation in many of the high-resolution downscaled simulations served as the impetus to investigate further, revealing that the driving RCM produces unphysical gridpoint storms in this region resulting from poorly parameterized mesoscale processes. The specific outstanding challenges listed here, in addition to further investigation into how to optimally initialize highresolution models from climate-scale datasets, remain topics of ongoing work.

\section{b. Discussion and future work}

The transition to smaller and smaller climate model grid spacings reveals new challenges in parameterizing convection and the small-scale processes that impact precipitation. When numerical weather models (e.g., higher-resolution models designed for the prediction of mesoscale weather) faced an analogous transition to higher model resolutions (e.g., Molinari and Dudek 1992), model errors were constantly scrutinized as part of the routine analysis of weather forecasting. While climate models are increasingly used for forecasting as well, opportunities to evaluate specific events are less common. As demonstrated here, detailed analysis of model performance for specific events (and in particular how key physical processes are represented in such events) can be a powerful complement to more standard climate model metrics that generally focus on longerterm means and variability.

Much of the potential value of a high-resolution individual event-based ingredients-focused climate downscaling framework lies in its ability to offer physical insight and test specific hypotheses. Additional applications in which such detail is ultimately useful is in driving dynamical runoff/hydrology models and creating scenarios of extreme events under certain climate change conditions (e.g., Barsugli et al. 2009; Porter et al. 2011; Waage and Kaatz 2011). This style of analysis also provides a diagnosis of driving model performance with respect to the skill of simulating extreme precipitation. To have confidence in a given model projection of the future, it is necessary to have confidence in the ability of the model to soundly represent critical physical processes. Distinguishing RCMs that produce extreme precipitation for physically plausible reasons from those that may demonstrate unrealistic errors because of poor parameterization performance could potentially be used to justify culling or weighting models in multimodel ensembles (e.g., Knutti et al. 2010; Mote et al. 2011; Bukovsky and Mearns 2012).

Several aspects of this study prompt future work to both improve this specific downscaling method and identify complementary research approaches to more fully explore changes in extreme precipitation for a given region. In this study, we focus only on the heaviest precipitation events in the 30-yr NARCCAP time windows, resulting in a limited sample size for statistical comparison. Therefore, the future changes in domain-average and domain-maximum precipitation shown in Tables 2 and 3 would likely be different if we were to have a larger sample size. The difficulty of pinning down a definitive trend speaks not only to the inherent variability in extreme events but also to the complex meteorology in this region, where several ingredients may control the future behavior of extreme precipitation. Nevertheless, a larger sample size of cases would allow statistical significance testing of trends, which would ideally include an evaluation of storm structure changes via more sophisticated metrics than those provided by local extreme value statistics. Climate change projections outside of those represented in the NARCCAP project (particularly the subset of three NARCCAP experiments utilized here) should also be sampled to the extent that resources permit. Event selection should also be further developed to include smaller-scale extreme events that are likely omitted in the current case identification method (because of the reliance on coarse-resolution parameterized model output). Work is ongoing to explore the utility of using observed historical small-scale events in a pseudoglobal warming perturbation framework (e.g., Lackmann 2013) to address this question. Future efforts could choose another parameter by which to select likely extreme event environments (although preliminary work using easterly wind speed convergence to identify upslope flow regimes did not significantly affect the results).

Differences between the RCM events and the observed record also suggest the possibility that the driving RCMs are producing events that are either too strong or are producing extreme precipitation in environments that might not support such precipitation in reality. Identifying and addressing such issues can be convoluted though, as events from RCM simulations based on GCM projections cannot be directly compared to observed events. Finally, many previous studies demonstrate that model skill in simulating past/present climate conditions is not a predictor of skill for future projections and that this issue is likely even more acute for the examination of extreme precipitation in particular (e.g., Jun et al. 2008; Santer et al. 2009; Knutti et al. 2010; Mote et al. 2011). This study has not endeavored to select a best model but rather to explore and evaluate consistency between a climate model's projected environment and its projected changes in extreme precipitation.

Despite the above considerations, judicious use of high-resolution model downscaling can contribute to 
addressing the pressing question of the local effects of climate change on extreme precipitation. The innovation and refinement of research techniques that use largescale climate data to answer small-scale physical processbased questions is both a challenge and an opportunity that scientists and stakeholders in the weather, climate, and water communities will increasingly share.

Acknowledgments. This research was supported by the Postdocs Applying Climate Expertise (PACE) Fellowship Program, administered by the University Corporation for Atmospheric Research, jointly funded by the National Oceanic and Atmospheric Administration (NOAA), the U.S. Bureau of Reclamation, and the Western Water Assessment, and also jointly by the U.S. Bureau of Reclamation and the Cooperative Institute for Research in Environmental Sciences (CIRES). Dr. Gary Lackmann of North Carolina State University is acknowledged for providing valuable comments on the manuscript, and the expertise and input of Dr. Mimi Hughes is also appreciated. The thoughtful insight and suggestions of three anonymous reviewers have significantly strengthened this work. We acknowledge NCAR and the National Science Foundation (NSF) for the availability of the WRF Model and NCL software. We also wish to thank the NARCCAP project for providing the RCM data used in this paper. NARCCAP is funded by the NSF, the U.S. Department of Energy (DOE), NOAA, and the U.S. Environmental Protection Agency Office of Research and Development (EPA). Gratitude is extended to the NOAA Jet and Zeus computing systems for providing computer resources for this work.

\section{REFERENCES}

Alexander, M., J. Scott, K. Mahoney, and J. Barsugli, 2013: Greenhouse gas-induced changes in summer precipitation over Colorado in NARCCAP regional climate models. J. Climate, 26, 8690-8697.

Baldwin, M. E., J. S. Kain, and M. P. Kay, 2002: Properties of the convective scheme in NCEP's Eta model that affect forecast sounding interpretation. Wea. Forecasting, 17, 1063-1079.

Barsugli, J., C. Anderson, J. B. Smith, and J. M. Vogel, 2009: Options for improving climate modeling to assist water utility planning for climate change. Water Utility Climate Alliance White Paper, 145 pp.

Bluestein, H. B., 1993: Observations and Theory of Weather Systems. Vol. 2, Synoptic-Dynamic Meteorology in Midlatitudes, Oxford University Press, $594 \mathrm{pp}$.

Bonnin, G. M., K. Maitaria, and M. Yekta, 2011: Trends in rainfall exceedances in the observed record in selected areas of the United States. J. Amer. Water Resour. Assoc., 47, 11731182 .

Brooks, H. E., C. A. Doswell III, and M. P. Kay, 2003: Climatological estimates of local daily tornado probability for the United States. Wea. Forecasting, 18, 626-640.
Bukovsky, M. S., 2012: Temperature trends in the NARCCAP regional climate models. J. Climate, 25, 3985-3991.

, and D. J. Karoly, 2007: A brief evaluation of precipitation from the North American Regional Reanalysis. J. Hydrometeor., 8, 837-846.

, and L. O. Mearns, 2012: Projections of climate change for the North American monsoon from the NARCCAP regional climate models. Preprints, 26th Conf. on Hydrology, New Orleans, LA, Amer. Meteor. Soc., J17.2. [Available online at https://ams.confex.com/ams/92Annual/flvgateway.cgi/id/ 19648? recordingid $=19648$.]

, J. S. Kain, and M. E. Baldwin, 2006: Bowing convective systems in a popular operational model: Are they for real? Wea. Forecasting, 21, 307-324.

Castro, C. L., R. A. Pielke Sr., and G. Leoncini, 2005: Dynamical downscaling: Assessment of value retained and added using the Regional Atmospheric Modeling System (RAMS). J. Geophys. Res., 110, D05108, doi:10.1029/2004JD004721.

Chao, W. C., 2012: Correction of excessive precipitation over steep and high mountains in a GCM. J. Atmos. Sci., 69, 1547-1561.

Cubasch, U., J. Waszkewitz, G. Hegerl, and J. Perlwitz, 1995: Regional climate changes as simulated time-slice experiments. Climatic Change, 31, 273-304

Del Genio, A. D., and J. Wu, 2010: The role of entrainment in the diurnal cycle of continental convection. J. Climate, 23, 2722-2738.

— W. Kovari, M.-S. Yao, and J. Jonas, 2005: Cumulus microphysics and climate sensitivity. J. Climate, 18, 2376-2387.

Dickinson, R. E., R. M. Errico, F. Giorgi, and G. T. Bates, 1989: A regional climate model for western United States. Climate Change, 15, 383-422.

Diffenbaugh, N. S., J. S. Pal, R. J. Trapp, and F. Giorgi, 2005: Finescale processes regulate the response of extreme events to global climate change. Proc. Natl. Acad. Sci. USA, 102, 15774-15 778.

Dominguez, F., E. Rivera, D. P. Lettenmaier, and C. L. Castro, 2012: Changes in winter precipitation extremes for the western United States under a warmer climate as simulated by regional climate models. Geophys. Res. Lett., 39, L05803, doi:10.1029/ 2011GL050762.

Doswell, C. A., III, 1987: The distinction between large-scale and mesoscale contribution to severe convection: A case study example. Wea. Forecasting, 2, 3-16.

— H. E. Brooks, and R. A. Maddox, 1996: Flash flood forecasting: An ingredients-based methodology. Wea. Forecasting, 11, 560-581.

Eckel, F. A., and C. F. Mass, 2005: Aspects of effective mesoscale, short-range ensemble forecasting. Wea. Forecasting, 20, 328-350.

Fowler, H. J., S. Blenkinsopa, and C. Tebaldi, 2007: Linking climate change modelling to impacts studies: Recent advances in downscaling techniques for hydrological modeling. Int. J. Climatol., 27, 1547-1578.

Frei, C., R. Schöoll, S. Fukutome, J. Schmidli, and P. L. Vidale, 2006: Future change of precipitation extremes in Europe: Intercomparison of scenarios from regional climate models. J. Geophys. Res., 111, D06105, doi:10.1029/2005JD005965.

Giorgi, F., 1991: Sensitivity of simulated summertime precipitation over the western United States to different parameterizations. Mon. Wea. Rev., 119, 2870-2888.

, and G. T. Bates, 1989: The climatological skill of a regional model over complex terrain. Mon. Wea. Rev., 117, 2325-2347.

Guichard, F., and Coauthors, 2004: Modelling the diurnal cycle of deep precipitating convection over land with cloud-resolving and single-column models. Quart. J. Roy. Meteor. Soc., 130, $3139-3172$ 
Gutmann, E. D., R. M. Rasmussen, C. Liu, K. Ikeda, D. J. Gochis, M. P. Clark, J. Dudhia, and G. Thompson, 2012: A comparison of statistical and dynamical downscaling of winter precipitation over complex terrain. J. Climate, 25, 262-281.

Gutowski, W. J., and Coauthors, 2010: Regional extreme monthly precipitation simulated by NARCCAP RCMs. J. Hydrometeor., 11, 1373-1379.

Hara, M., T. Yoshikane, H. Kawase, and F. Kimura, 2008: Estimation of the impact of global warming on snow depth in Japan by the pseudo-global warming method. Hydrol. Res. Lett., 2, 61-64.

Haylock, M. R., G. C. Cawley, C. Harpham, R. L. Wilby, and C. M. Goodess, 2006: Downscaling heavy precipitation over the United Kingdom: A comparison of dynamical and statistical methods and their future scenarios. Int. J. Climatol., 26, 13971415.

Hill, K. A., and G. M. Lackmann, 2011: The impact of future climate change on TC intensity and structure: A downscaling approach. J. Climate, 24, 4644-4661.

Hohenegger, C., P. Brockhaus, C. S. Bretherton, and C. Schär, 2009: The soil moisture-precipitation feedback in simulations with explicit and parameterized convection. J. Climate, 22, 5003-5020.

Hossain, F., I. Jeyachandran, and R. A. Pielke Sr., 2010: Dam safety effects due to human alteration of extreme precipitation. Water Resour. Res., 46, W03301, doi:10.1029/2009WR007704.

Hostetler, S. W., J. R. Alder, and A. M. Allan, 2011: Dynamically downscaled climate simulations over North America: Methods, evaluation, and supporting documentation for users. U.S. Geological Survey Open-File Rep. 2011-1238, 64 pp. [Available online at http://pubs.usgs.gov/of/2011/1238/.]

Hughes, M., P. J. Neiman, E. Sukovich, and F. M. Ralph, 2012: Representation of the Sierra barrier jet in 11 years of a highresolution dynamical reanalysis downscaling compared with long-term wind profiler observations. J. Geophys. Res., 117, D18116, doi:10.1029/2012JD017869.

Jun, M., R. Knutti, and D. W. Nychka, 2008: Spatial analysis to quantify numerical model bias and dependence: How many climate models are there? J. Amer. Stat. Assoc., 103, 934-947, doi:10.1198/016214507000001265.

Karl, T. R., G. A. Meehl, C. D. Miller, S. J. Hassol, A. M. Waple, and W. L. Murray, Eds., 2008: Weather and climate extremes in a changing climate: Regions of focus: North America, Hawaii, Caribbean, and U.S. Pacific Islands. U.S. Climate Change Science Program Rep., 162 pp.

Kawase, H., T. Yoshikane, M. Hara, F. Kimura, T. Yasunari, B. Ailikun, H. Ueda, and T. Inoue, 2009: Intermodel variability of future changes in the baiu rainband estimated by the pseudo global warming downscaling method. J. Geophys. Res., 114, D24110, doi:10.1029/2009JD011803.

Kendon, E. J., N. M. Roberts, C. A. Senior, and M. J. Roberts, 2012: Realism of rainfall in a very high-resolution regional climate model. J. Climate, 25, 5791-5806.

Knutti, R., R. Furrer, C. Tebaldi, J. Cermak, and G. A. Meehl, 2010: Challenges in combining projections from multiple climate models. J. Climate, 23, 2739-2758.

Lackmann, G. M., 2013: The South-Central U.S. flood of May 2010: Present and future. J. Climate, 26, 4688-4709.

Lenderink, G., and E. van Meijgaard, 2008: Increase in hourly precipitation extremes beyond expectations from temperature changes. Nat. Geosci., 1, 511-514.

, and - , 2010: Linking increases in hourly precipitation extremes to atmospheric temperature and moisture changes. Environ. Res. Lett., 5, 025208, doi:10.1088/1748-9326/5/2/025208.
Leung, L. R., and Y. Qian, 2009: Atmospheric rivers induced heavy precipitation and flooding in the western U.S. simulated by the WRF regional climate model. Geophys. Res. Lett., 36, L03820, doi:10.1029/2008GL036445.

Li, J., S. Sorooshian, W. Higgins, X. Gao, B. Imam, and K. Hsu, 2008: Influence of spatial resolution on diurnal variability during the North American monsoon. J. Climate, 21, 3967-3988.

Liang, X.-Z., J. Pan, J. Zhu, K. E. Kunkel, J. X. L. Wang, and A. Dai, 2006: Regional climate model downscaling of the U.S. summer climate and future change. J. Geophys. Res., 111, D10108, doi:10.1029/2005JD006685.

Mahoney, K. M., and G. M. Lackmann, 2006: The sensitivity of numerical forecasts to convective parameterization: A case study of the 17 February 2004 East Coast cyclone. Wea. Forecasting, 21, 465-488.

_ , and _ 2007: The effect of upstream convection on downstream precipitation. Wea. Forecasting, 22, 255-277.

- M. A. Alexander, G. Thompson, J. Barsugli, and J. Scott, 2012: Changes in hail and flood risk in high-resolution simulations over Colorado's mountains. Nat. Climate Change, 2, 125-131, doi:10.1038/nclimate1344.

Marsh, P. T., H. E. Brooks, and D. J. Karoly, 2007: Assessment of the severe weather environment in North America simulated by a global climate model. Atmos. Sci. Lett., 8, 100-106.

,-- , and -2009 : Preliminary investigation into the severe thunderstorm environment of Europe simulated by the Community Climate System Model 3. Atmos. Res., 93, 607-618.

Mearns, L. O., W. Gutowski, R. Jones, R. Leung, S. McGinnis, A. Nunes, and Y. Qian, 2009: A regional climate change assessment program for North America. Eos, Trans. Amer. Geophys. Union, 90, 311-312.

__ and Coauthors, cited 2011: The North American Regional Climate Change Assessment Program dataset. National Center for Atmospheric Research Earth System Grid data portal. [Available online at http://dx.doi.org/10.5065/D6RN35ST.]

Mesinger, F., and Coauthors, 2006: North American Regional Reanalysis. Bull. Amer. Meteor. Soc., 87, 343-360.

Milly, P. C. D., J. Betancourt, M. Falkenmark, R. M. Hirsch, Z. W. Kundzewicz, D. P. Lettenmaier, and R. J. Stouffer, 2008: Stationarity is dead: Whither water management? Science, 319, 573-574.

Molinari, J., and M. Dudek, 1992: Parameterization of convective precipitation in mesoscale numerical models: A critical review. Mon. Wea. Rev., 120, 326-344.

Moncrieff, M. W., and C. Liu, 2006: Representing convective organization in prediction models by a hybrid strategy. J. Atmos. Sci., 63, 3404-3420.

Mote, P., L. Brekke, P. B. Duffy, and E. Maurer, 2011: Guidelines for constructing climate scenarios. Eos, Trans. Amer. Geophys. Union, 92, 257, doi:10.1029/2011EO310001.

Nakicenovic, N., and R. Swart, Eds., 2000: Emission scenarios. Special Report on Emissions Scenarios, Cambridge University Press, 239-292.

Newman, A. J., and R. H. Johnson, 2012: Simulation of a North American monsoon Gulf surge event and comparison to observations. Mon. Wea. Rev., 140, 2534-2554.

O'Gorman, P. A., and T. Schneider, 2009: The physical basis for increases in precipitation extremes in simulations of twentyfirst-century climate change. Proc. Natl. Acad. Sci. USA, 106, 14773-14777.

Ohara, N., M. Kavvas, S. Kure, Z. Chen, S. Jang, and E. Tan, 2011: Physically based estimation of maximum precipitation over American River watershed, California. J. Hydrol. Eng., 16, 351-361, doi:10.1061/(ASCE)HE.1943-5584.0000324. 
Pal, J. S., and Coauthors, 2007: Regional climate modeling for the developing world: The ICTP RegCM3 and RegCNET. Bull. Amer. Meteor. Soc., 88, 1395-1409.

Pall, P., M. R. Allen, and D. A. Stone, 2007: Testing the ClausiusClapeyron constraint on changes in extreme precipitation under $\mathrm{CO}_{2}$ warming. Climate Dyn., 28, 351-363.

Porter, K., and Coauthors, 2011: Overview of the ARkStorm scenario. U.S. Geological Survey Open-File Rep. 2010-1312, 183 pp.

Pritchard, M. S., M. W. Moncrieff, and R. C. J. Somerville, 2011: Orogenic propagating precipitation systems over the United States in a global climate model with embedded explicit convection. J. Atmos. Sci., 68, 1821-1840.

Rasmussen, R. M., and Coauthors, 2011: High-resolution coupled climate runoff simulations of seasonal snowfall over Colorado: A process study of current and warmer climate. J. Climate, 24, 3015-3048.

Salzmann, N., and L. O. Mearns, 2012: Assessing the performance of multiple regional climate model simulations for seasonal mountain snow in the upper Colorado River basin. J. Hydrometeor., 13, 539-556.

Santer, B. D., and Coauthors, 2009: Incorporating model quality information in climate change detection and attribution studies. Proc. Natl. Acad. Sci. USA, 106, 14778-14783, doi:10.1073/ pnas.0901736106.

Schär, C., C. Frie, D. Lüthi, and H. C. Davies, 1996: Surrogate climate-change scenarios for regional climate models. Geophys. Res. Lett., 23, 669-672.

Skamarock, W. C., J. B. Klemp, J. Dudhia, D. O. Gill, D. M. Barker, W. Wang, and J. G. Powers, 2007: A description of the Advanced Research WRF version 2. NCAR Tech. Note NCAR/TN-475+STR, 125 pp.

Toth, J. J., and R. H. Johnson, 1985: Summer surface flow characteristics over northeast Colorado. Mon. Wea. Rev., 113, 1458-1469.

Trapp, R. J., N. S. Diffenbaugh, H. E. Brooks, M. E. Baldwin, E. D. Robinson, and J. S. Pal, 2007a: Changes in severe thunderstorm environment frequency during the 21st century caused by anthropogenically enhanced global radiative forcing. Proc. Natl. Acad. Sci. USA, 104, 19719-19723, doi:10.1073/ pnas.0705494104.

_ B. Halvorson, and N. S. Diffenbaugh, 2007b: Telescoping, multimodel approaches to evaluate extreme convective weather under future climates. J. Geophys. Res., 112, D20109, doi:10.1029/2006JD008345.
— N. S. Diffenbaugh, and A. Gluhovsky, 2009: Transient response of severe thunderstorm forcing to elevated greenhouse gas concentrations. Geophys. Res. Lett., 36, L01703, doi:10.1029/ 2008GL036203.

—, E. D. Robinson, M. E. Baldwin, N. S. Diffenbaugh, and B. R. J. Schwedler, 2010: Regional climate of hazardous convective weather through high-resolution dynamical downscaling. Climate Dyn., 37, 677-688, doi:10.1007/s00382-010-0826-y.

Trier, S. B., C. A. Davis, and D. A. Ahijevych, 2010: Environmental controls on the simulated diurnal cycle of warm-season precipitation in the continental United States. J. Atmos. Sci., 67, 1066-1090.

Van Klooster, S. L., and P. J. Roebber, 2009: Surface-based convective potential in the contiguous United States in a businessas-usual future climate. J. Climate, 22, 3317-3330.

Waage, M. D., and L. Kaatz, 2011: Nonstationary water planning: An overview of several promising planning methods. J. Amer. Water Resour. Assoc., 47, 535-540, doi:10.1111/ j.1752-1688.2011.00547.x.

Wang, S.-Y., R. R. Gillies, E. S. Takle, and W. J. Gutowski Jr., 2009: Evaluation of precipitation in the intermountain region as simulated by the NARCCAP regional climate models. Geophys. Res. Lett., 36, L11704, doi:10.1029/2009GL037930.

Wehner, M. F., 2013: Very extreme seasonal precipitation in the NARCCAP ensemble: Model performance and projections. Climate Dyn., 40, 59-80, doi:10.1007/s00382-012-1393-1.

_ , R. Smith, P. Duffy, and G. Bala, 2010: The effect of horizontal resolution on simulation of very extreme US precipitation events in a global atmosphere model. Climate Dyn., 32, 241-247.

West, G. L., W. J. Steenburgh, and W. Y. Y. Cheng, 2007: Spurious grid-scale precipitation in the North American Regional Reanalysis. Mon. Wea. Rev., 135, 2168-2184.

Williams, E. R., and N. Renno, 1993: An analysis of the conditional instability of the tropical atmosphere. Mon. Wea. Rev., 121, 21-36.

Ye, B., A. Del Genio, and K. Lo, 1998: CAPE variations in the current climate and in a climate change. J. Climate, 11, 19972015

Zhang, D.-L., E.-Y. Hsie, and M. W. Moncrieff, 1988: A comparison of explicit and implicit prediction of convective and stratiform precipitating weather systems with a meso$\beta$-scale numerical model. Quart. J. Roy. Meteor. Soc., 114, $31-60$. 